\title{
Experimentally Validated Numerical Modeling of Heat Transfer in Granular Flow in Rotating Vessels
}

\author{
Bodhisattwa Chaudhuri ${ }^{1}$, Fernando J. Muzzio ${ }^{2}$ and M. Silvina Tomassone ${ }^{2}$ \\ ${ }_{1}^{1}$ Department of Pharmaceutical Sciences, University of Connecticut, Storrs, CT, 06269 \\ 2Department of Chemical and Biochemical Engineering, Rutgers University, Piscataway, \\ NJ, 08854 \\ United States of America
}

\section{Introduction}

Heat transfer in particulate materials is a ubiquitous phenomenon in nature, affecting a great number of applications ranging from multi-phase reactors to kilns and calciners. The materials used in these type of applications are typically handled and stored in granular form, such as catalyst particles, coal, plastic pellets, metal ores, food products, mineral concentrates, detergents, fertilizers and many other dry and wet chemicals. Oftentimes, these materials need to be heated and cooled prior to or during processing. Rotary calciners are most commonly used mixing devices used in metallurgical and catalyst industries (Lee, 1984; Lekhal et. al., 2001). They are long and nearly horizontal rotating drums that can be equipped with internal flights (baffles) to process various types of feedstock. Double cone impregnators are utilized to incorporate metals or other components into porous carrier particles while developing supported catalysts. Subsequently, the impregnated catalysts are heated, dried and reacted in rotating calciners to achieve the desired final form. In these processes, heat is generally transferred by conduction and convection between a solid surface and particles that move relative to the surface. Over the last fifty years, there has been a continued interest in the role of system parameters and in the mechanisms of heat transfer between granular media and the boundary surfaces in fluidized beds (Mickey \& Fairbanks, 1955; Basakov, 1964; Zeigler \& Agarwal, 1969; Leong et.al., 2001; Barletta et. al., 2005), dense phase chutes, hoppers and packed beds (Schotte, 1960; Sullivan \& Sabersky, 1975; Broughton \& Kubie, 1976; Spelt et. al., 1982; Patton et. al., 1987; Buonanno \& Carotenuto, 1996; Thomas et. al., 1998; Cheng et. al., 1999), dryers and rotary reactors and kilns (Wes et. al., 1976; Lehmberg et. al., 1977). More recently, experimental work on fluidized bed calciner and rotary calciners/kilns have been reported by LePage et.al, 1998; Spurling et.al., 2000, and Sudah. et al., 2002. In many of these studies, empirical correlations relating bed temperature to surface heat transfer coefficients for a range of operating variables have been proposed. Such correlations are of restricted validity because they cannot be easily generalized to different equipment geometries and it is risky to extrapolate their use outside the experimental range of variables studied. Moreover, most of these models do not capture particle-surface interactions or the detailed microstructure of the 
granular bed. Since the early 1980s, several numerical approaches have been used to model granular heat transfer methods using (i) kinetic theory (Natarajan \& Hunt, 1996) (ii) continuum approaches (Michaelides, 1986; Ferron \& Singh, 1991; Cook \& Cundy, 1995, Natarajan \& Hunt, 1996, Hunt, 1997) and (iii) discrete element modeling (DEM) (Kaneko et. al., 1999; Li \& Mason, 2000; Vargas \& McCarthy, 2001; Skuratovsky et. al., 2005). The constitutive model based on kinetic theory incorporates assumptions such as isotropic radial distribution function, a continuum approximation and purely collisional interactions amongst particles, which are not completely appropriate in the context of actual granular flow. Continuum models neglect the discrete nature of the particles and assume a continuous variation of matter that obeys the laws of conservation of mass and momentum. To the best of our knowledge, among continuum approaches, only Cook and Cundy, 1995 modeled heat transfer of a moist granular bed inside a rotating vessel. Continuum-based models can yield accurate results for the time-averaged quantities such as velocity, density and temperature while simulating heat transfer in granular material, but fail to reveal the behavior of individual particles and do not consider inter-particle interactions.

In the discrete element model, each constituent particle is considered to be distinct. DEM explicitly considers inter-particle and particle-boundary interactions, providing an effective tool to solve the transient heat transfer equations. Most of the DEM-based heat transfer work has been either two-dimensional or in static granular beds. To the best of our knowledge no previous work has used three-dimensional DEM to study heat transfer in granular materials in rotary calciners (with flights attached) that are the subject of this study. Moreover, a laboratory scale rotary calciner is used to estimate the effect of various materials and system parameters on heat transfer, which also helps to validate the numerical predictions.

\section{Experimental setup}

A cylindrical tubing ( 8 inches outer diameter, 6 inches inner diameter and 3 inches long) of aluminum is used as the "calciner" for our experiments. The calciner rides on two thick Teflon wheels (10 inches diameter) placed at the two ends of the calciner, precluding the direct contact of the metal wall with the rollers used for rotating the calciner. The side and the lateral views of the calciner are shown in Figure $1 \mathrm{a}$ and $1 \mathrm{~b}$ respectively. Figure 1a also shows how the ten thermocouples are inserted vertically into the calciner with their positions being secured at a constant relative position (within themselves) using a rectangular aluminum bar attached to the outer Teflon wall of the calciner. Twelve holes are made on the Teflon wall of the calciner where the two holes at the end are used to secure the aluminum bar with screws, whereas, the intermediate holes allow the insertion of 10 thermocouples (as shown in Fig 1c). The other end-wall of Teflon has a thick glass window embedded for viewing purpose. In Figure $1 d$, the internals of the calciner comprising the vertical alignment of 10 thermocouples is visible through the glass window. Thermocouples are arranged radially due to the radial variation of temperature during heat transfer in the granular bed as observed in our earlier simulations (Chaudhuri et.al, 2006). The thermocouples are connected to the Omega 10 channel datalogger that works in unison with the data acquisition software of the adjacent PC. $200 \mu \mathrm{m}$ size alumina powder and cylindrical silica particles ( $2 \mathrm{~mm}$ diameter and $3 \mathrm{~mm}$ long) are the materials used in our experiments. The calciner is initially loaded with the material of interest. Twenty to fifty percent of the drum is filled with granular material during the experiments. At room 
temperature, an industrial heat gun is used to uniformly heat the external wall of the calciner. The calciner is rotated using step motor controlled rollers, while the wall temperature is maintained at $100^{\circ} \mathrm{C}$. At prescribed intervals, the "calciner" is stopped to insert the thermocouples inside the granular bed to take the temperature readings. Once temperature is recorded, the thermocouples are extracted and rotation is initiated again.

\section{Numerical model and parameter used}

The Discrete Element Method (DEM), originally developed by Cundall and Strack (1971, 1979), has been used successfully to simulate chute flow (Dippel, et.al., 1996), heap formation (Luding, 1997), hopper discharge (Thompson and Grest, 1991; Ristow and Hermann, 1994), blender segregation (Wightman, et.al, 1998; Shinbrot, 1999; Moakher, 2000) and flows in rotating drums (Ristow, 1996; Wightman, et.al., 1998). In the present study DEM is used to simulate the dynamic behavior of cohesive and non-cohesive powder in a rotating drum (calciner) and double cone (impregnator). Granular material is considered here as a collection of frictional inelastic spherical particles. Each particle may interact with its neighbors or with the boundary only at contact points through normal and tangential forces. The forces and torques acting on each of the particles are calculated as:

$$
\begin{gathered}
\sum F_{i}=m_{i} g+F_{n}+F_{t}+F_{\text {cohes }} \\
\sum T_{i}=r_{i} \times F_{T}
\end{gathered}
$$

Thus, the force on each particle is given by the sum of gravitational, inter-particle (normal and tangential: $F_{N}$ and $F_{T}$ ) and cohesive forces as indicated in Eq. (1). The corresponding torque on each particle is the sum of the moment of the tangential forces $\left(F_{T}\right)$ arising from inter-particle contacts (Eq. (2)).

We use the "latching spring model" to calculate normal forces. This model, developed by Walton and Braun (1986, 1992, 1993), allows colliding particles to overlap slightly. The normal interaction force is a function of the overlap. The normal forces between pairs of particles in contact are defined using a spring with constants $K_{1}$ and $K_{2}: F_{N}=K_{1} \alpha_{1}$ (for compression), and $F_{N}=K_{2}\left(\alpha_{1}-\alpha_{0}\right)$ (for recovery). These spring constants are chosen to be large enough to ensure that the overlaps $\alpha_{1}$ and $\alpha_{0}$ remain small compared to the particles sizes. The degree of inelasticity of collisions is incorporated in this model by including a coefficient of restitution $e=\left(K_{1} / K_{2}\right)^{1 / 2} \quad(0<e<1$, where $e=1$ implies perfectly elastic collision with no energy dissipation and $e=0$ implies completely inelastic collision).

Tangential forces $\left(F_{T}\right)$ in inter-particle or particle-wall collision are calculated with Walton's incrementally slipping model. After contact occurs, tangential forces build up, causing displacement in the tangential plane of contact. These forces are assumed to obey Coulomb's law. The initial tangential stiffness is considered to be proportional to the normal stiffness. If the magnitude of tangential forces is greater than the product of the normal force by the coefficient of static friction, (i.e. $T \geq \mu \mathrm{F}_{\mathrm{N}}$ ) sliding takes place with a constant coefficient of dynamic friction. The model also takes into account the elastic deformation that can occur in the tangential direction. The tangential force $T$ is evaluated considering an effective tangential stiffness $k_{T}$ associated with a linear spring. It is incremented at each time step as $T_{t+1}=T_{t}+k_{t} \Delta s$, where $\Delta s$ is the relative tangential displacement between two time steps (for details on the definition of $\Delta s$ see Walton (1993)). The described model was used 
successfully to perform three-dimensional simulations of granular flow in realistic blender geometries, where it confirmed important experimental observations (Wightman, et.al., 1998, Moakher, et. al., 2000, Shinbrot, et.al., 1999; Sudah, et.al., 2005).

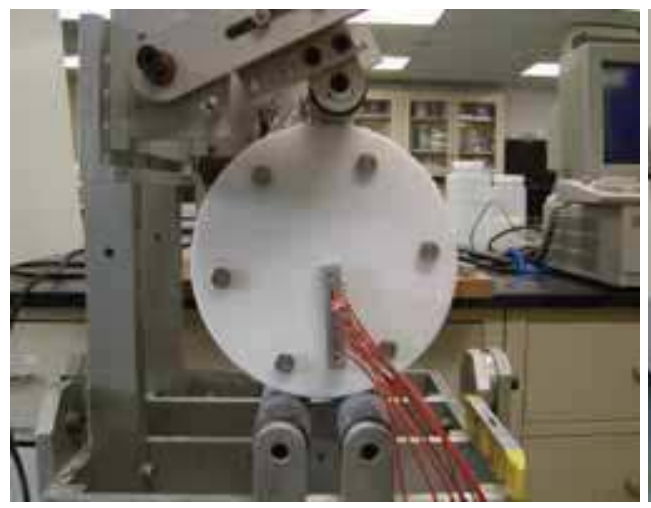

(a)

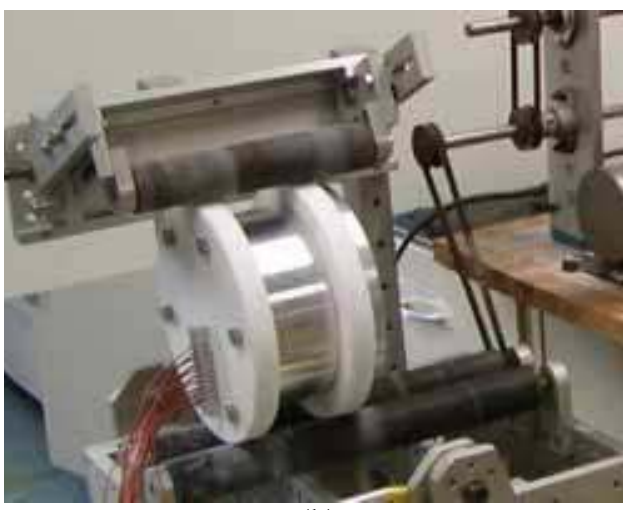

(b)

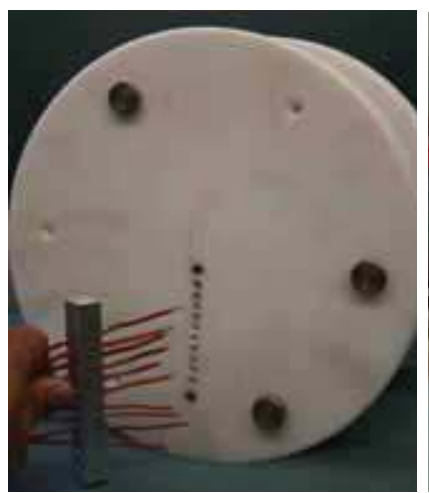

(c)

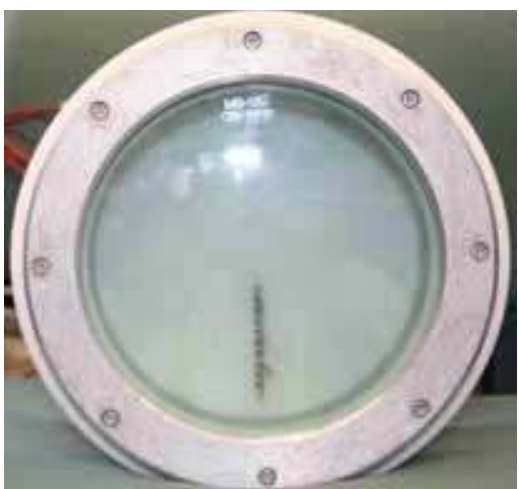

(d)

Fig. 1. (a) Aluminum calciner on rollers (side view) showing 10 thermocouples inserted within the calciner through the Teflon side-wall. (b) Lateral view of the calciner. (c) 10 thermocouples are tied up to the metal rod which is being attached to the teflon wall. Vertically located, ten holes are also shown in the teflon wall through which thermocouples are inserted inside the calciner. (d) Another side view showing the internals of the calciner and the vertical alignment of 10 thermocouples which are visible through the glass window.

We also incorporate cohesive forces between particles in our model using a square-well potential. In order to compare simulations considering different numbers of particles, the magnitude of the force was represented in terms of the dimensionless parameter $K=F_{\text {cohes }} / m g^{1}$, where $K$ is called the bond number and is a measure of cohesiveness that is

\footnotetext{
${ }^{1}$ Notice that we are not claiming that cohesive forces depend on the particle weight. This is just a convenient way of defining how strong cohesion is, as compared to the particle weight (i.e. 20 times the weight, 30 times the weight, etc)
} 
independent of particle size, $\mathrm{F}_{\text {cohes }}$ is the cohesive force between particles, and $\mathrm{mg}$ is the weight of the particles. Notice that this constant force may represent short range effects 2 such as electrostatic or van der Waals forces. In this model, the cohesive force $\left(F_{\text {cohes }}\right)$ between two particles or between a particle and the wall is unambiguously defined in terms of K. Four friction coefficients need to be defined: particle-particle and particle-wall static and dynamic coefficients. Interestingly, (and unexpectedly to the authors) all four friction coefficients turn out to be important to the transport processes.

Heat transport within the granular bed may take place by: thermal conduction within the solid; thermal conduction through the contact area between two particles in contact; thermal conduction through the interstitial fluid; heat transfer by fluid convection; radiation heat transfer between the surfaces of particles. Our work is focused on the first two mechanisms of conduction which are expected to dominate when the interstitial medium is stagnant and composed of a material whose thermal conductivity is small compared to that of the particles. O'Brien (1977) estimated this assumption to be valid as long as $\left(k_{S} a / k_{f} r\right)>>1$, where $a$ is the contact radius, $\mathrm{r}$ is the particle radius of curvature, $\mathrm{k}_{\mathrm{f}}$ denotes the fluid interstitial medium conductivity and $k_{S}$ is the thermal conductivity of the solid granular material. This condition is identically true when $k_{f}=0$, that is in vacuum.

Heat transport processes are simulated accounting for initial material temperature, wall temperature, granular heat capacity, granular heat transfer coefficient, and granular flow properties (cohesion and friction). Heat transfer is simulated using a linear model, where the flux of heat transported across the mutual boundary between two particles $i$ and $j$ in contact is described as

$$
Q_{i j}=H_{c}\left(T_{j}-T_{i}\right)
$$

Here. $T_{i}$ and $T_{j}$ are the temperatures of the two particles and the inter-particle conductance $\mathrm{H}_{\mathrm{c}}$ is:

$$
H_{c}=2 k_{S}\left[\frac{3 F_{N} r^{*}}{4 E^{*}}\right]^{1 / 3}
$$

where $\mathrm{ks}_{\mathrm{s}}$ is the thermal conductivity of the solid material, $\mathrm{E}^{*}$ is the effective Young's modulus for the two particles, and $r^{*}$ is the geometric mean of the particle radii (from Hertz's elastic contact theory). The evolution of temperature of particle i from its neighbor ( $j$ ) is

$$
\frac{d T_{i}}{d t}=\frac{Q_{i}}{\rho_{i} C_{i} V_{i}}
$$

Here, $Q_{i}$ is the sum of all heat fluxes involving particle $i$ and $\rho_{i} C_{i} V_{i}$ is the thermal capacity of particle i.

Equations (3-5) can be used to predict the evolution of each particle's temperature for a flowing granular system in contact with hot or cold surfaces. The algorithm is used to examine the evolution of the particle temperature both in the calciner and the double cone impregnator. This numerical model is developed based on following assumptions:

\footnotetext{
${ }^{2}$ Improvement of this model can be achieved by including electrostatic forces explicitly. We are currently working on this extension, and the results will be published in a separate article.
} 
1. Interstitial gas is neglected.

2. Physical properties such a heat capacity, thermal conductivity and Young Modulus are considered to be constant.

3. During each simulation time step, temperature is uniform in each particle (Biot Number well below unity).

4. Boundary wall temperature remains constant.

The major computational tasks at each time step are as follows: (i) add/delete contact between particles, thus updating neighbor lists, (ii) compute contact forces from contact properties, (iii) compute heat flux using thermal properties (iv) sum all forces and heat fluxes on particles and update particle position and temperatures, and (v) determine the trajectory of the particle by integrating Newton's laws of motion (second order scalar equations in three dimensions). A central difference scheme, Verlet's Leap Frog method, is used here.

The computational conditions and physical parameters considered are summarized in Table 1. Heat transport in alumina is simulated for the experimental validation work, and then copper is chosen as the material of interest for

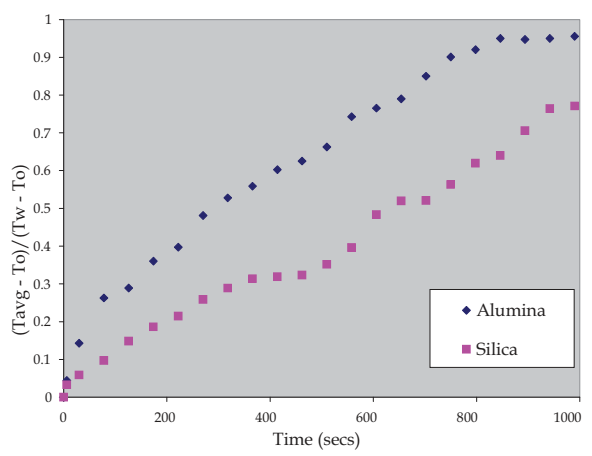

(a)

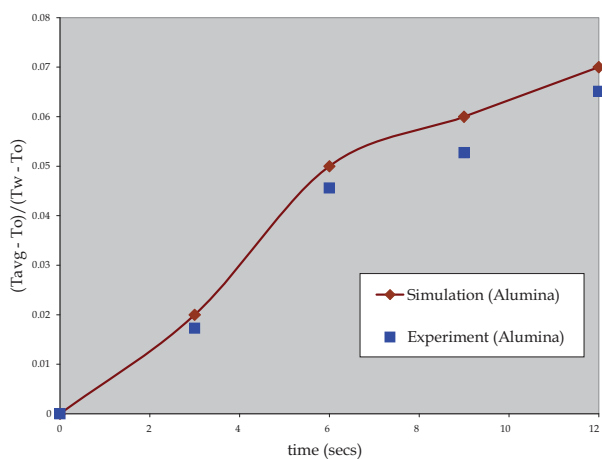

(b)

Fig. 2. (a) Variation of average bed temperature with time for alumina and silica; (b)

Evolution of average bed temperature for simulation and experiments with alumina. The fill level of the calciner is $50 \%$ and is rotated at $20 \mathrm{rpm}$ in the experiments and simulations

further investigation on baffle size/orientation in calciners and impregnators.We simulated the flow and heat transfer of 20,000 particles of $1 \mathrm{~mm}$ size rotated in the calciner equipped with or without baffle of variable shapes. The calciner consists of a cylindrical 6 inch diameter vessel with length of 0.6 inches, intentionally flanked with frictionless side walls to simulate a thin slice of the real calciner, devoid of end-wall effects. Two baffle sizes are considered (of thicknesses equal to $3 \mathrm{~cm}$ and $6 \mathrm{~cm}$ ). The initial surface temperature of all the particles is considered to be $298 \mathrm{~K}$ (room temperature) whereas the temperature of the wall (and the baffle in the impregnator) is considered to be constant, uniform, and equal to 1298 $\mathrm{K}$. The computational conditions and physical parameters considered are summarized in Table 1. Initially particles were loaded into the system and allowed to reach mechanical equilibrium. Subsequently, the temperature of the vessel was suddenly raised to a desired value, and the evolution of the temperature of each particle in the system was recorded as a function of time. 
The double cone impregnator model considers flow and heat transfer of 18,000 particles of $3 \mathrm{~mm}$ diameter in a vessel of $25 \mathrm{~cm}$ diameter and $30 \mathrm{~cm}$ length. The cylindrical portion of the impregnator is $25 \mathrm{~cm}$ diameter and $7.5 \mathrm{~cm}$ long. Each of the conical portions is $11.25 \mathrm{~cm}$ long and makes an angle of $45^{\circ}$ with the vertical axis. The diameter at the top or bottom of the impregnator is $2.5 \mathrm{~cm}$ The effect of baffle size is investigated in impregnators. Intuitively, the baffle is kept at an angle $45^{\circ}$ with respect to the axis of rotation. The length of the baffle is $25 \mathrm{~cm}$, same as the diameter of the cylindrical portion of the impregnator. The width and thickness of the baffle are equal to one another (square cross section).

In order to describe quantitatively the dynamics of evolution of the granular temperature field, the following quantities were computed:

- $\quad$ Particle temperature fields vs. time

- $\quad$ Average bed temperature vs. time

- Variance of particle temperatures vs. time

These variables were examined as a function of relevant parameters, and used to examine heat transport mechanisms in both of the systems of interest here

\section{Results and discussions}

\subsection{Effect of thermal properties in calciners}

The effect of thermal conductivity in heat transfer is examined using alumina and silica particles separately, each occupying $50 \%$ of the calciner volume. The calciner is rotated at the speed of $20 \mathrm{rpm}$. The average bed temperature $\left(\mathrm{T}_{\mathrm{avg}}\right)$ is estimated as the mean of the readings of the ten thermocouples and scaled with the average wall temperature $\left(T_{w}\right)$ and the average initial condition $\left(T_{0}\right)$ of the particle bed to quantify the effect of thermal conductivity. In Figure 2a, as expected, alumina with higher thermal conductivity warms up faster than silica. DEM simulations are performed with the same value for the physical and thermal properties of the material used in the experiments (for Alumina: thermal conductivity: $\mathrm{k}_{\mathrm{s}}=35 \mathrm{~W} / \mathrm{mK}$ and heat capacity: $\mathrm{Cp}=875 \mathrm{~J} / \mathrm{KgK}$, for Silica: $\mathrm{K}=14 \mathrm{~W} / \mathrm{mK}$, $\mathrm{Cp}=740 \mathrm{~J} / \mathrm{KgK})$. The initial surface temperature of all the particles is considered to be $298 \mathrm{~K}$ (room temperature) whereas the temperature of the wall is kept constant and equal to $398 \mathrm{~K}$ (in isothermal conditions). The DEM simulations predict the temperature of each of the particles in the system, thus the average bed temperature $\left(\mathrm{T}_{\mathrm{avg}}\right)$ in simulation is the mean value of the predicted temperature of all the particles. Figure $(2 b)$ shows the variation of scaled average bed temperature for both simulation and experiments. The predictions of our simulation show a similar upward trend to the experimental findings.

\subsection{Effect of vessel speed in the calciner}

Alumina and silica powders are heated at varying vessel speed of 10, 20 and $30 \mathrm{rpm}$. The wall is heated and maintained at $100^{\circ} \mathrm{C}$. Figure $3(\mathrm{a})$ and $3(\mathrm{~b})$ show the evolution of average bed temperature with time as a function of vessel speed for alumina and silica respectively. The average bed temperatures for all the cases follow nearly identical trends. The external wall temperature is maintained at a constant temperature of $100^{\circ} \mathrm{C}$. Figure (3c) shows the variation of scaled average bed temperature for simulation.

All experimental temperature measurements were performed every 30 seconds; with a running time of 1200 seconds. However, each of our simulation runs was performed for 
only 12 seconds. Assuming a dispersion coefficient $E \sim \frac{L^{2}}{T}$ to be constant [Bird et. al., 1960;

Crank, 1976], where L and T are the length and time scales, respectively, of the microscopic transitions that generate scalar transport, then the time required to achieve a certain progress of a temperature profile is proportional to the square of the transport microscale. The radial transport length scale used in the simulations, if measured in particle diameters, is much smaller than in the experiment, and correspondingly, the time scale needed to achieve a comparable progress of the temperature profile is much shorter, as presented in Figures 3a-c. In fact, the ratio of time scales between the experiment and the simulation probably is same to the ratio of length scales squared, shown by calculation below.

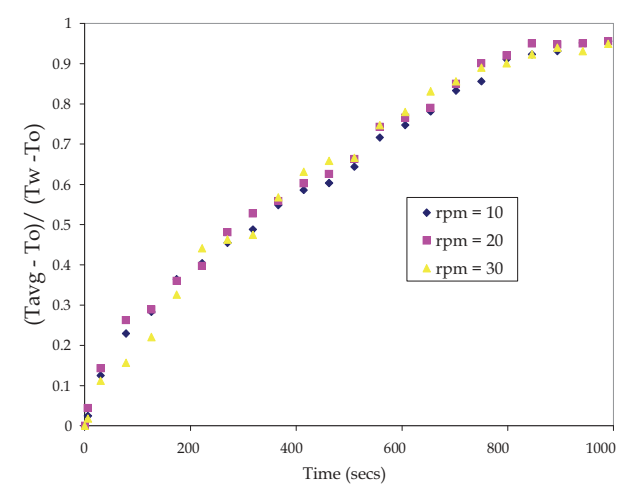

(a)

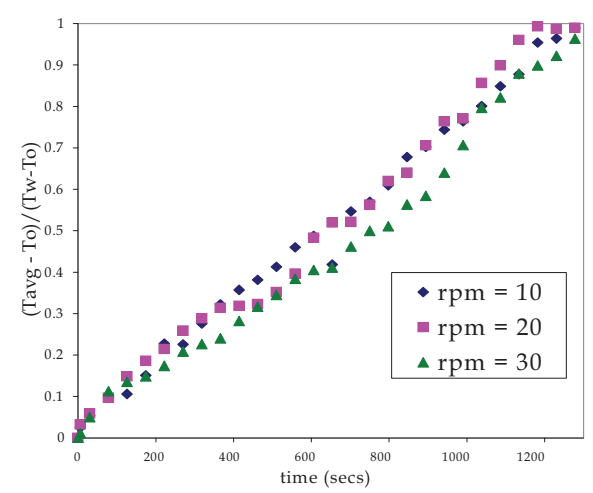

(b)

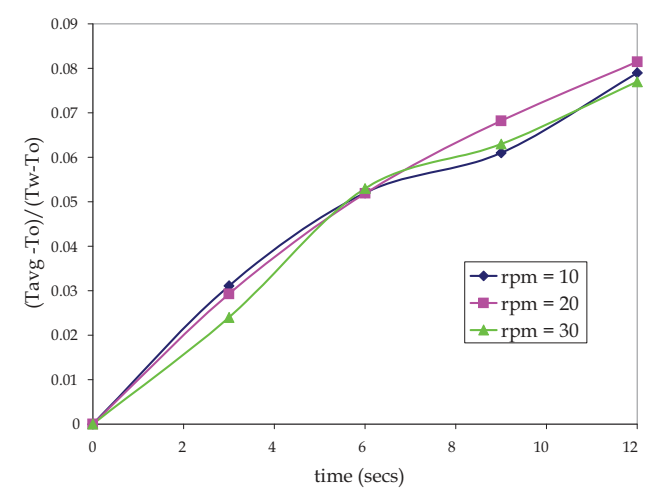

(c)

Fig. 3. Variation of temperature with time as a function of vessel speed for (a) Alumina (b) silica and (c) model with alumina.

In the experiments, the diameter of the vessel $(D e)$, duration of the experiment $(T e)$ and particle size (de) are 6 inches, 1200 seconds and 200 microns (alumina) respectively. Whereas, in the simulations, the diameter of the vessel (Ds), time of the simulation (Ts) and particle size $(d s)$ are 6 inches, 12 seconds and $2 \mathrm{~mm}$ respectively. Ratios of time and length scales are estimated as below: 
Ratio of time scales $\left(\mathrm{R}_{\mathrm{T}}\right): \frac{T e}{T s}=\frac{1200}{12}=100$

Ratio of length scales $\left(\mathrm{R}_{\mathrm{L}}\right): \frac{L_{e}}{L_{s}}=\frac{\frac{D_{e}}{d_{e}}}{\frac{D_{s}}{d_{s}}}=\frac{\frac{6}{0.2}}{\frac{6}{2}}=10$

Therefore, $\mathrm{R}_{\mathrm{T}}=\left(\mathrm{R}_{\mathrm{L}}\right)^{2}$

Although there is a big difference in the time scale in the plots of our experiments (Fig. 3a or Fig. 3b) and simulations (Fig. 3c), they still exhibit the same transport phenomena in different time scales. The predictions of our simulation show the same upward trend similar to the experimental findings, even though, they are plotted in different time scales. The nominal effect of vessel speed on heat transfer was also observed by Lybaert, 1986, in his experiments with silica sand or glass beads heated in rotary drum heat exchangers.

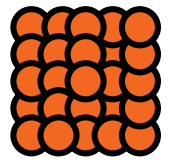

(a)

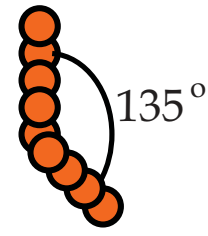

(b)

Fig. 4. Baffles are formed with particles glued together (a) square cross-section and (b) L-shaped cross section.

\subsection{Effect of baffles on heat transfer in calciners using a DEM model}

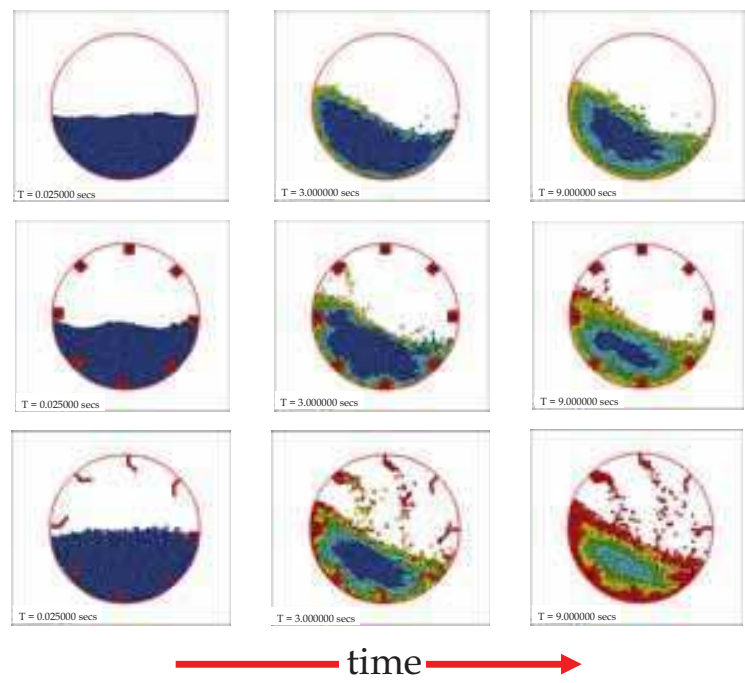

Fig. 5. Time sequence of axial snapshots 
Section 4.3 is focused on our particle simulations only. After validation of the model, presented in last two subsections, a parametric study is conducted by varying the size and the orientation of the baffles of the calciner using the same DEM model. The evolution of particle temperature is visually track using color-coding. Particles with temperature lower than $350^{\circ} \mathrm{K}$ are colored blue; those with temperatures between $350^{\circ} \mathrm{K}$ and $550^{\circ} \mathrm{K}$ are painted cyan; those with temperatures between $550^{\circ} \mathrm{K}$ and $750^{\circ} \mathrm{K}$ are colored green and for temperatures between $750^{\circ} \mathrm{K}$ and $950^{\circ} \mathrm{K}$, particles are colored yellow. Particles with temperatures higher than $950^{\circ} \mathrm{K}$ are colored red.

Figure 5 shows a time sequence of axial snapshots of color-coded particles in the calciner. Time increases from left to right $(t=0,3$ and 9 secs), while the baffle design vary from top to bottom.

\subsubsection{Effect of baffle shape in heat transfer}

In this section we study the effect of baffle shape in the calcination process. We do this by extending the DEM model of a calciner without baffles (which was previously validated) to one that which now effectively incorporates baffles. In our model, baffles or flights are attached to the inner wall of the calciner of radius $15 \mathrm{~cm}$ and length of $1.6 \mathrm{~cm}$. Baffles run longitudinally along the axial direction of the calciner. We consider 8000 copper particles of radius $2 \mathrm{~mm}$ heated in the calciner which rotates are $20 \mathrm{rpm}$ for various baffle designs. The initial temperature of the particles is chosen to be at room temperature $\left(298^{\circ} \mathrm{K}\right)$. We simulate baffles of two different cross sections, i.e. rectangular and L-shaped by rigidly grouping particles of $2 \mathrm{~mm}$ size, which perform solid body rotation with the calciner wall. Fig 4 depicts the composition of the different baffles.

We construct the baffle particles purposely overlapping with each other by $10 \%$ of their diameter, to nullify any inter-particle gap which may cause smaller particles to percolate through the baffle. The square shaped baffle of cross sectional area of approximately $58 \mathrm{~mm}^{2}$ and $340 \mathrm{~mm}^{2}$ are designed by arranging a matrix of 2 by 2 particles and 5 by 5 particles respectively. The L-shaped baffle is constructed by 9 particles bonded in a straight line until the $5^{\text {th }}$ particle and then arranging the remaining 4 particles in an angle of $135^{\circ}$. Baffle particles also remain at the same temperature of the wall, i.e. $1298^{\circ} \mathrm{K}$.

For visual representation, particles are color-coded based on their temperature. In Figure 5, the axial snapshots captured at time $t=0,1$ and 3 revolutions for 3 different baffle configurations: (i) no baffle (ii) baffles of each $400 \mathrm{~mm}^{2}$ cross sectional area (iii) 8 L-shaped flights. The blue core displays the larger mass of particles at initial temperature. This cold core shrinks with time for all cases, however, the volume of the blue core shrinks faster for calciner with L shaped baffles. The number of red particles present in the bed increases for calciners with L-shaped baffles. Thus, increased surface area of the bigger baffle enhances in heat transfer within the calciners.

The effect of baffle configuration on heat transfer is quantified with our DEM model by measuring the average bed temperature as a function of time for all baffle configurations. Average bed temperature rises faster for calciners with L-shaped baffles, as seen in Figure 6(a). The uniformity of the temperature of the particle bed is quantified by estimating the standard deviation of the temperature of the bed. Figure $6(\mathrm{~b})$ shows the effect of the baffle configuration on the uniformity of the bed temperature. The L-shaped baffles scoops up more particles in comparison to the square shaped baffle and helps in breaking the quasistatic zone in the center of the granular bed and redistributing the particles onto the cascading layer causing rapid mixing (uniformity) within the bed. 


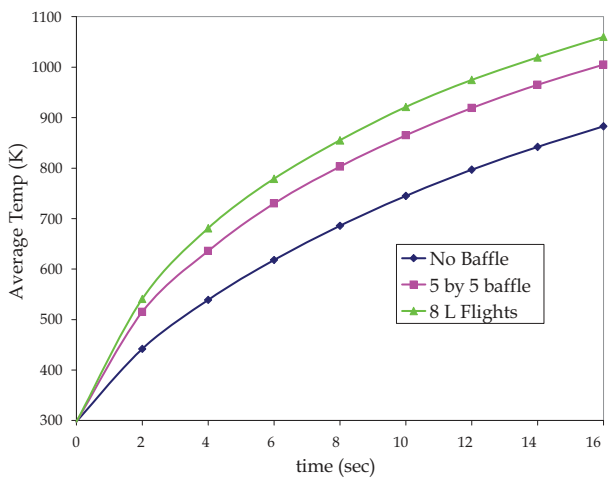

(a)

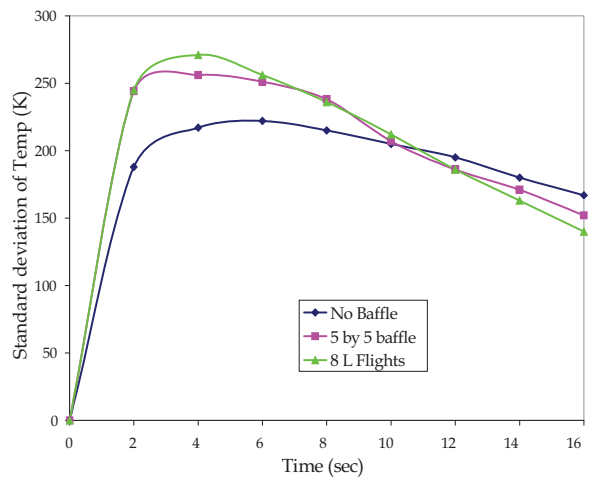

(b)

Fig. 6. (a): Average temperature as function of time for different baffle configurations. (b): Standard deviation versus time for different baffle configurations.

\subsubsection{Effect of baffle size on heat transfer in calciners}

The effect of the size of the rectangular baffles/flights is investigated using DEM simulations. In Figure 7, the axial snapshots captured at time $T=0,1$ and 3 revolutions for 3 different baffle configurations: (i) no baffle (ii) 8 baffles of each $64 \mathrm{~mm}^{2}$ cross sectional area (iii) 8 baffles of each $400 \mathrm{~mm}^{2}$ cross sectional area. In our DEM model, four (2 by 2) and twenty-five ( 5 by 5) particles of radius $2 \mathrm{~mm}$ are glued together to form each of the baffles in case (ii) and (iii) respectively. The blue core signifies the mass of particles at initial temperature.

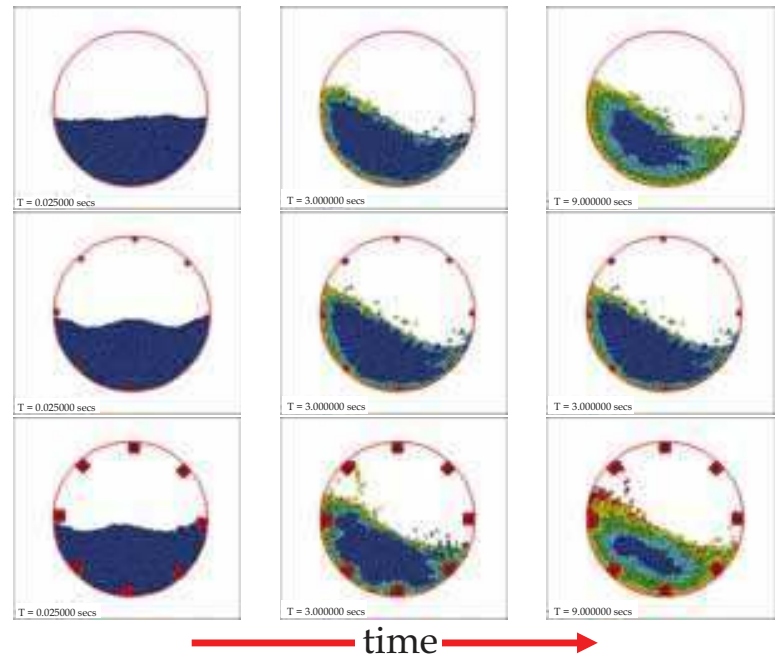

Fig. 7. shows a time sequence of axial snapshots of color-coded particles in the calciner. Time increases from left to right $(t=0,3$ and 9 secs), while the baffle size increases top to bottom 
This cold core shrinks with time for all cases, but it shrinks faster for a calciner with bigger baffles. The number of red particles in the bed also increases for calciners with baffles of bigger sizes. Thus, increased surface area of the bigger baffle enhances heat transfer within the calciners. The effect of baffle size on heat transfer is quantified by calculating the average bed temperature as a function of time for all baffle configurations. Average bed temperature rises faster for calciners with bigger baffles, as seen in Figure 8(a). The uniformity of the temperature of the particle bed is quantified by estimating the standard deviation of the bed temperature. Figure $8(\mathrm{~b})$ shows the effect of the baffle size on the uniformity of the bed temperature, systems with bigger baffles reach uniformity quicker.

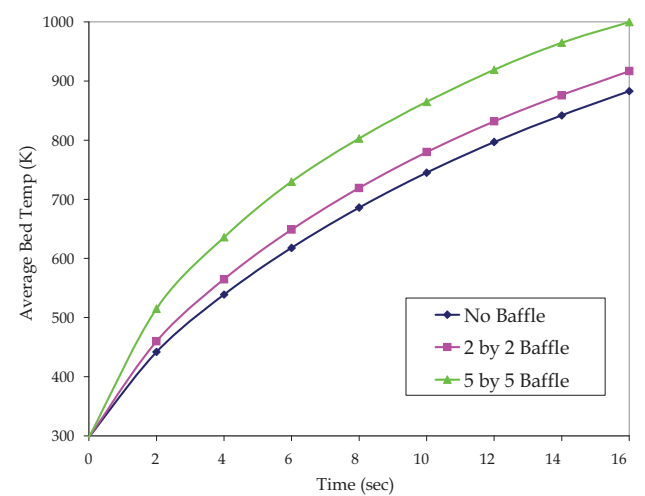

(a)

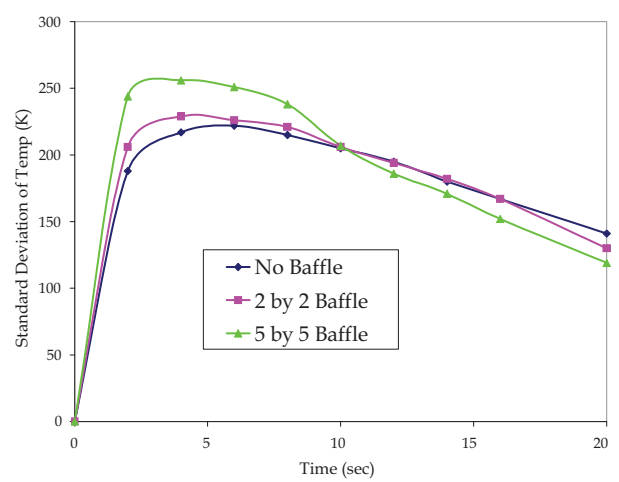

(b)

Fig. 8. (a): Average bed temperature as a function of time for different sizes of rectangular baffles (b): The evolution of standard deviation versus time for different baffle configurations.

\subsubsection{Effect of number of baffles/flights on heat transfer in calciners}

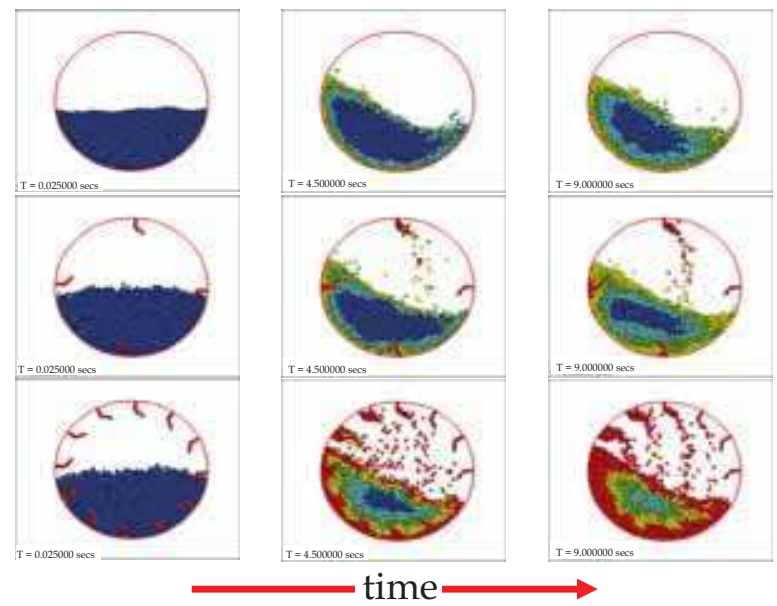

Fig. 9. Evolution of the temperature for non-baffled and baffled calciners (with 4 and 8 flights) at time $=0,1.5$ and 3 revs. 
The number of baffles is an important geometric parameter for the rotary calciner. The effect of the parameter has been investigated with a calciner with L-shaped baffles. We calculated the evolution of the temperature depicted in successive snapshots for 0,4 and 12 baffles in Fig 9. There is a cold core which shrinks with time for all the cases, and it shrinks faster for the calciner with larger number of baffles. The number of red particles present in the bed also increases for calciners with more baffles. Thus, increase in the number of baffles causes enhancement in heat transfer within the calciners. The effect of number of baffles on heat transfer is quantified by calculating the average bed temperature as a function of time for all baffle configurations. The average temperature of the bed rises faster for calciners with higher number of baffles. This can be seen in Figure 10(a). The uniformity of the temperature of the powder bed is quantified by estimating the standard deviation of the surface temperature of the bed and it is shown in Figure 10(b). It can be seen that the thermal uniformity of the bed is directly proportional to the number of baffles.

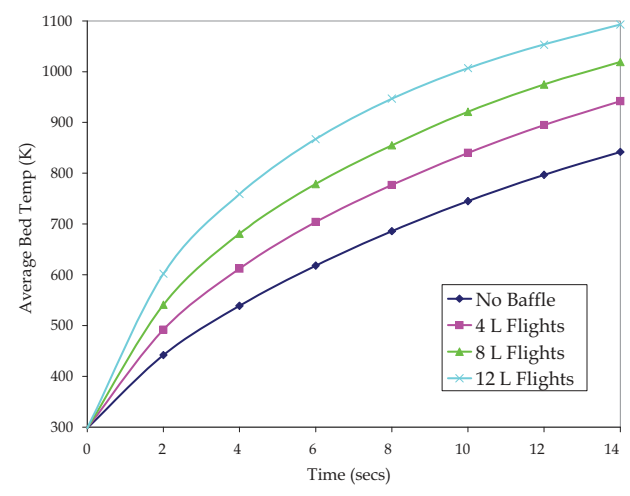

(a)

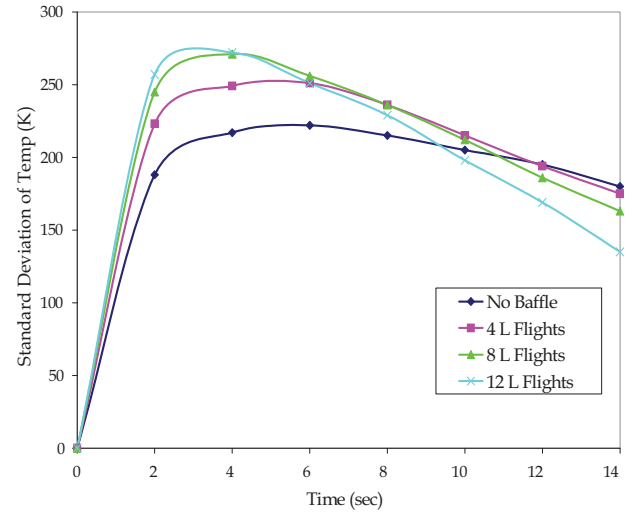

(b)

Fig. 10. (a): Effect of number of L-Shaped baffles on heat transfer. (b): The evolution of standard deviation versus time for different baffle configurations

\subsubsection{Effect of speed in baffled calciners:}

Heat transfer as a function of vessel speed is examined for L-shaped baffles. The evolution of temperatures of the particles is estimated for calciners with $8 \mathrm{flights} /$ baffles rotated at different speeds: 10, 20 and $30 \mathrm{rpm}$ (shown in Fig 11). The cold core gets smaller with time for all the cases, but this reduction is faster for calciners rotated at higher speed. The number of red particles present in the bed also increases for calciners rotating with higher speed. Thus, an increase in the speed enhances heat transfer within the calciners. The effect of speed on heat transfer is quantified by means of the average bed temperature as a function of time for all baffle configurations. Average bed temperature rises faster for calciners with higher speeds, as seen in Figure 12(a). This observation contradicts previous observations for un-baffled calciners. The higher vessel speed ensures more scooping of the material inside the bed and redistribution of the particles per unit of time, by the L-shaped baffles. The uniformity of the temperature of the particle bed is quantified by estimating the standard deviation of the surface temperature of the bed. As expected, bed rotated at higher speed reaches thermal uniformity faster (see Fig. 12(b)). 

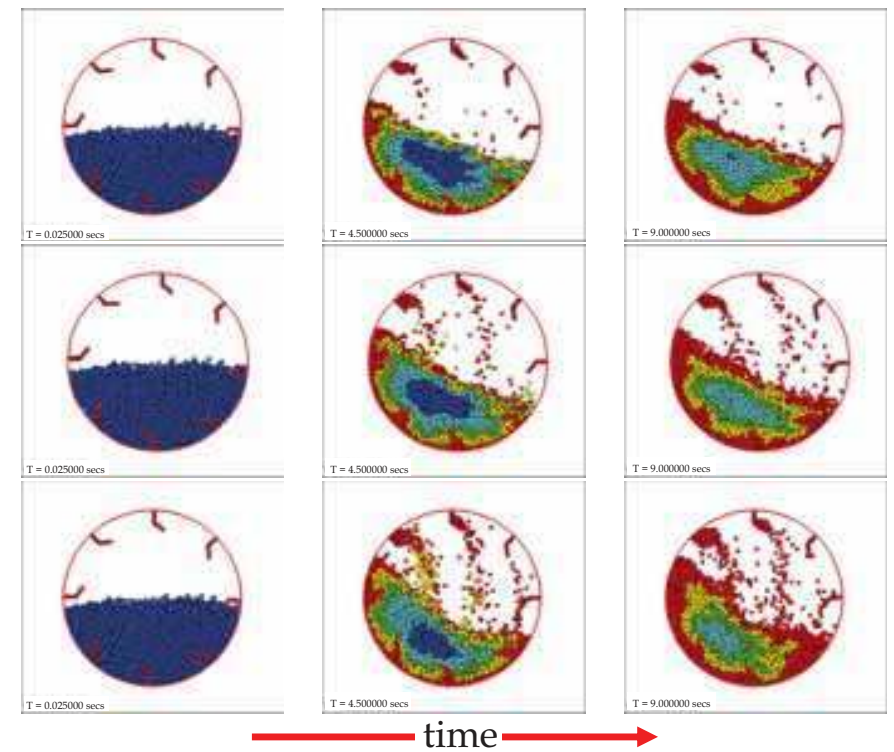

$\mathrm{rpm}=10$

$\mathrm{rpm}=20$

$\mathrm{rpm}=30$

Fig. 11. Evolution of temperature for baffled calciners (8 flights) at different rotational speeds of 10, 20 and $30 \mathrm{rpm}$, for different values of time $=0,4.5$ and 9 secs.

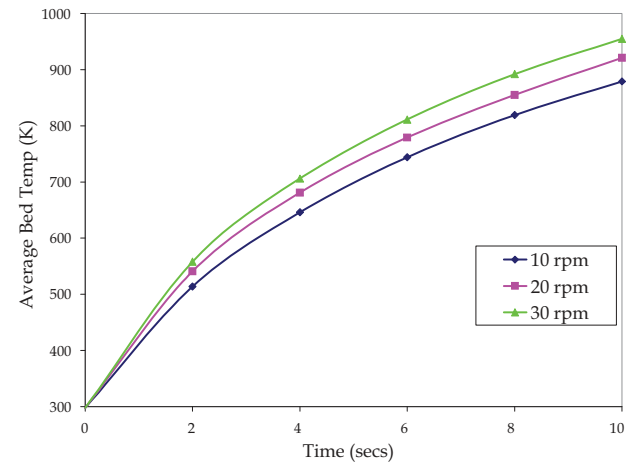

(a)

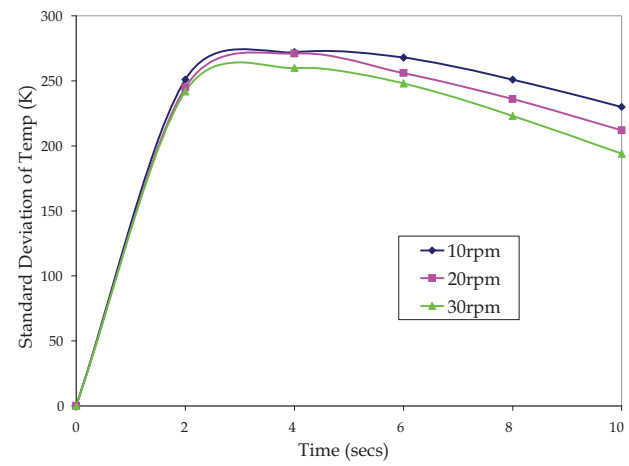

(b)

Fig. 12. (a): Effect of speed on heat transfer for calciners with L-Shaped baffles. (b): The evolution of the standard deviation versus time for different vessel speeds.

\subsubsection{Effect of adiabatic baffles on heat transfer in calciners}

In the previous simulations all baffles were always at the wall temperature and enhanced the heat transfer and thermal uniformity (mixing) in the calciners. However, this can be due to two distinct effects. The flights not only scoop and redistribute particles enhancing convective transport, but also heat up the particles during the contact, increasing area for conductive transport. To nullify the conduction effect and check how flights affect convective heat transfer, L-shaped baffles were maintained at an adiabatic condition in a 
particle-baffle contact, $\mathrm{dQ}=0$ is considered. The 8 flights are thus maintained at the room temperature $(298 \mathrm{~K})$ whereas, the wall remains at 1298 K. In Figure 13, the axial snapshots are displayed at time $\mathrm{T}=0,4$ secs and 8 seconds for 2 different baffle configurations: (i) $8 \mathrm{~L}$ shaped baffles at room temperature $(298 \mathrm{~K})$ (ii) 8 L-shaped flights at the wall temperature $(1298 \mathrm{~K})$. The blue core signifies the mass of particles at the initial temperature. This cold core shrinks with time for all the cases, but it shrinks faster for calciners with L-shaped baffles at wall temperature. The number of red particles present in the bed also increases for calciners with L-shaped baffles at wall temperature (shown in the left column in Fig 13).
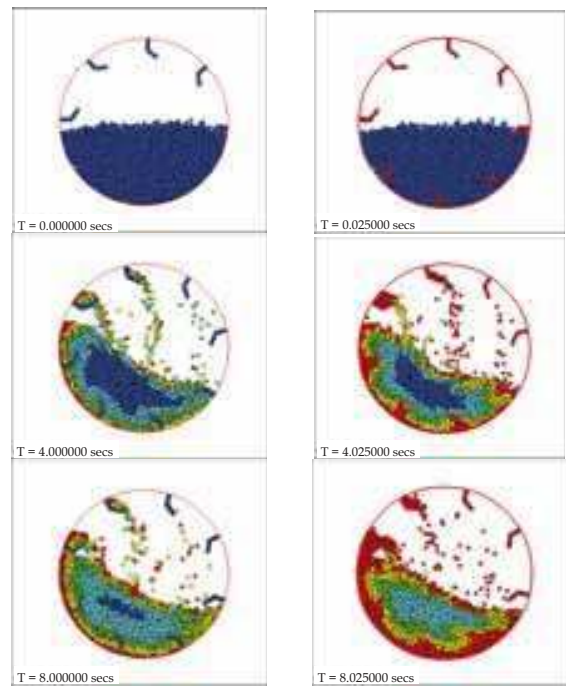

Fig. 13. The axial snapshots of the calciners with cold (left) and hot baffles (right) at different time intervals.

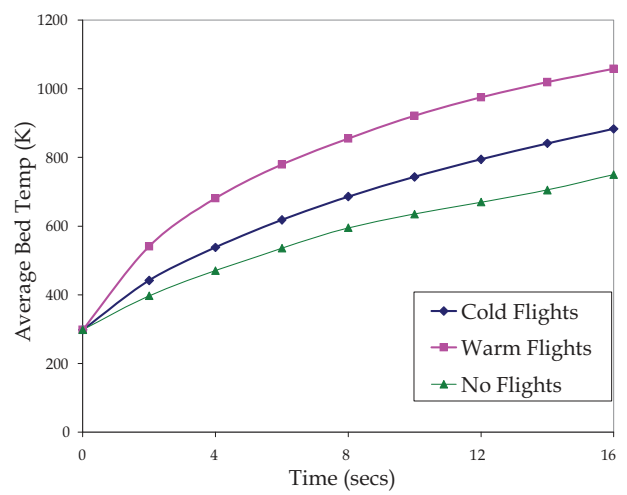

(a)

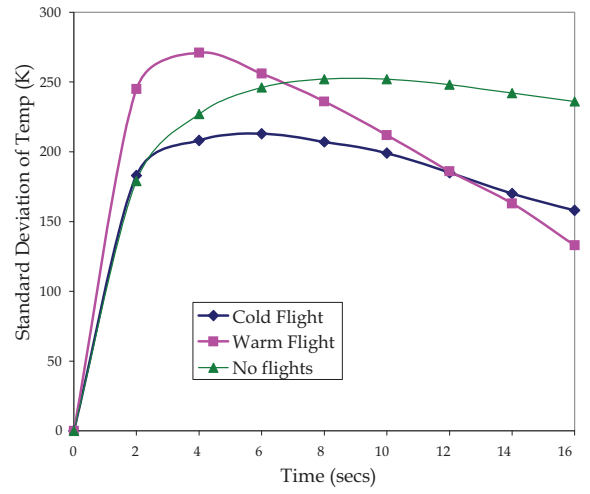

(b)

Fig. 14. (a): The evolution of average bed temperature for $8 \mathrm{~L}$ shaped cold and warm flights and unbaffled calciners. (b): The evolution of thermal uniformity for calciners with cold, warm baffled and unbaffled flights. 
Thus, heated baffles enhance heat transfer within the calciners. The effect of the temperature of the baffle on heat transfer is quantified by calculating the average bed temperature as a function of time for all baffle configurations and comparing it with the temperature profile of the non-baffled calciner. The average bed temperature rises faster for calciners with Lshaped baffles at wall temperature, but the calciner with colder baffle shows faster heat transport than non-baffled calciners (see Figure 14(a)). In Figure 14b, the uniformity of the temperature of the particle bed is presented by estimating the standard deviation of the surface temperature of the bed. The calciners with flights are reaching thermal uniformity faster than the non-baffled calciners. The temperature of the baffle does not cause much difference in thermal uniformity as both the curves for baffled calciners are very close to each other (convective mixing effect is independent of baffle temperature)

\subsection{Heat transfer of copper particles in the calciner}

Initially, 16,000 particles are loaded into the system in a non-overlapping fashion and allowed to reach mechanical equilibrium under gravitational settling. Subsequently, the vessel is rotated at given rate, and the evolution of the position and temperature of each particle in the system is recorded as a function of time. The curved wall is considered to be frictional. To minimize the finite size effects the flat end walls are considered frictionless and not participating in heat transfer. A parametric study was conducted by varying thermal conductivity, particle heat capacity, granular cohesion, vessel fill ratio, and vessel speed of the calciner. A cohesive granular material $\left(\mathrm{K}_{\text {cohes }}=75, \mu_{\mathrm{SP}}=0.8, \mu_{\mathrm{DP}}=0.6, \mu_{\mathrm{SW}}=0.8, \mu_{\mathrm{DW}}=\right.$ 0.8 ) is considered to examine the effect of thermal properties and the speed of the vessel. Particles with temperature lower than $350^{\circ} \mathrm{K}$ are colored blue; those with temperature in between $350^{\circ} \mathrm{K}$ and $550^{\circ} \mathrm{K}$ are considered cyan. Those with temperature between $550^{\circ} \mathrm{K}$ and $750^{\circ} \mathrm{K}$ are considered green and for temperatures between $750^{\circ} \mathrm{K}$ and $950^{\circ} \mathrm{K}$ are considered yellow. Those particles with temperature higher than $950^{\circ} \mathrm{K}$ are colored red.

\subsubsection{Effect of thermal conductivity}

Three values of thermal conductivity of the solid material are considered: $96.25,192.5,385$ $\mathrm{W} / \mathrm{m}^{\circ} \mathrm{K}$. The calciner is rotated at the speed of $20 \mathrm{rpm}$. As the heat source is the wall, the particle bed warms up from the region in contact to the wall. Particle-wall contacts cause the transport of heat from the wall to the particle bed. With subsequent particle-particle contacts, heat is transported inside the bed. In Figure 15a, the axial snapshots captured at time $\mathrm{T}=0,0.5$ and 1 revolutions for varying thermal conductivities are displayed. The combination of heat transfer and convective particle motion results in rings or striations as the temperature decrease from the wall to the core of the bed. The presence of these concentric striations signifies that under the conditions examined here, the dominant mechanism is radial conductive transport of heat from the wall to the core of the bed. The blue core signifies the mass of particles at initial temperature. This cold core shrinks with time, as expected; the volume of the blue core shrinks faster for higher particle conductivities. The average bed temperature is illustrated in Figure (15d). As conductivity increases, the system exhibits faster heating. The variation of the standard deviation of the temperature of the bed is illustrated on Fig. 15 (e). Uniformity in the bed temperature increases with conductivity until the end of 5 revolutions. Finally the bed with higher conductivity rapidly reaches a thermal equilibrium with the isothermal wall, where all the particles in bed reach the wall temperature and there is no more heat transfer. 


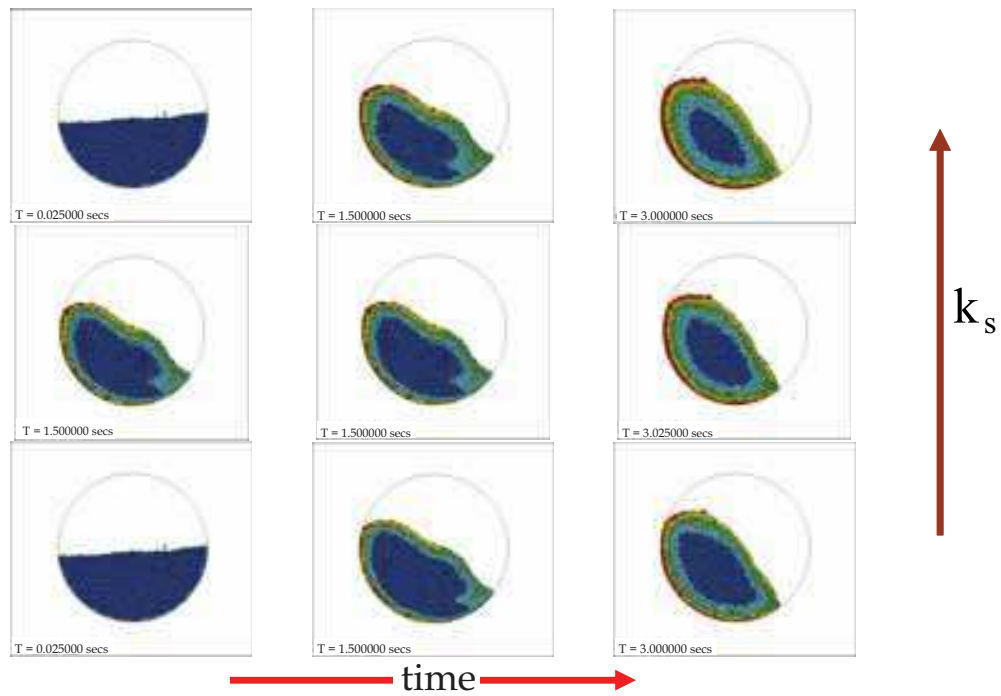

(a)

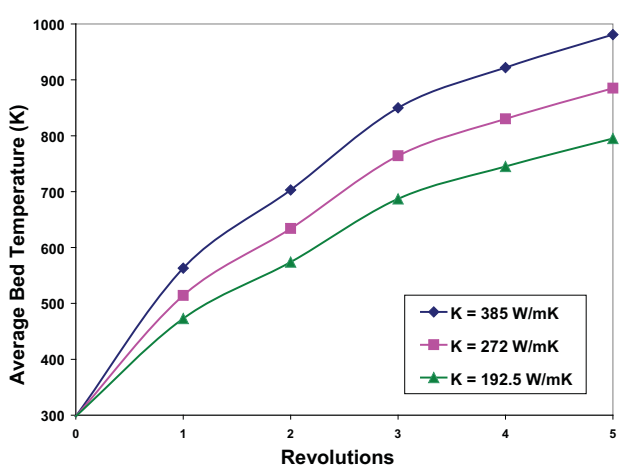

(b)

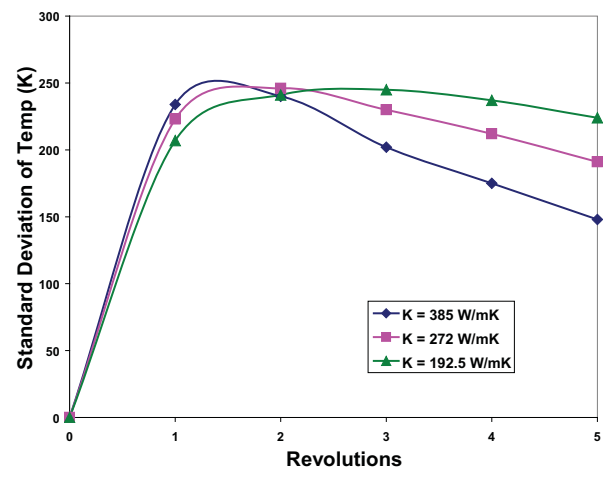

(c)

Fig. 15. (a) shows a time sequence of axial snapshots of color-coded particles in the calciner. Time increases from left to right $(t=0,1.5$ and 3 secs), while the thermal conductivity increases from bottom to top $\left(\mathrm{k}_{\mathrm{s}}=192.5,272,385 \mathrm{~W} / \mathrm{mK}\right)$. (b) shows the growth of average bed temperature over time for materials with different conductivity. The granular bed heats up faster for material with higher conductivity. (c). illustrates the variation of the standard deviation of particle temperature over time for different conductivities. More uniformity of temperature in the bed for material of higher thermal conductivity.

A physical formula to fit the simulation prediction is derived based on the LevenbergMarquardt method, which uses non-linear least square based regression techniques. This curve fitting method is employed for the average bed temperature data displayed in Fig 1 for the highest thermal conductivity $\left(k_{s}=385 \mathrm{~W} / \mathrm{mK}\right)$. The $3 \mathrm{rd}$ order polynomial derived is as follows 


$$
T_{\text {avg }}=301.92+288.624 n-45.05 n^{2}+2.9 n^{3}
$$

where $T_{\text {avg }}$ and $n$ are the average bed temperature and number of revolutions respectively. The vessel speed for this data is $20 \mathrm{rpm}$ and so $n=1$ corresponds to 3 seconds. The correlation coefficient for this fit $\mathrm{R}=0.9989$. The simulation data and the $3^{\text {rd }}$ order least square fit curve of the data are illustrated in Fig. 15d.To gather an insight of the evolution of average bed temperatures beyond 5 revolutions, the average bed temperatures at all time intervals for each of the cases in Fig. 15b is scaled by the corresponding average temperature at 5 revolutions. In Fig. 15e, almost all of the data points for different conductivity overlap showing the evolution of average temperature follow the same shape and will reach thermal equilibrium with the wall at the same rate shown in Fig. 15b.

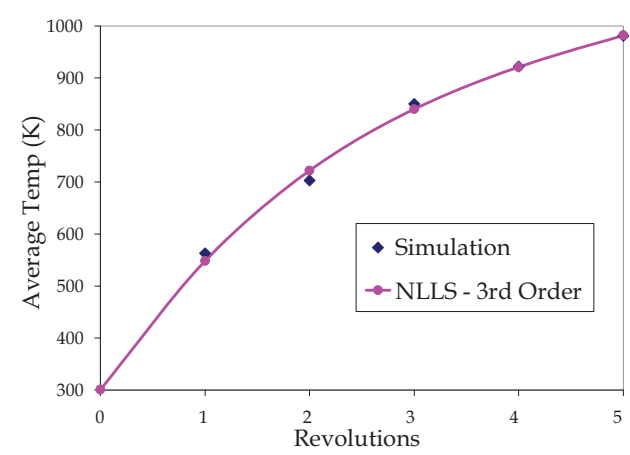

(d)

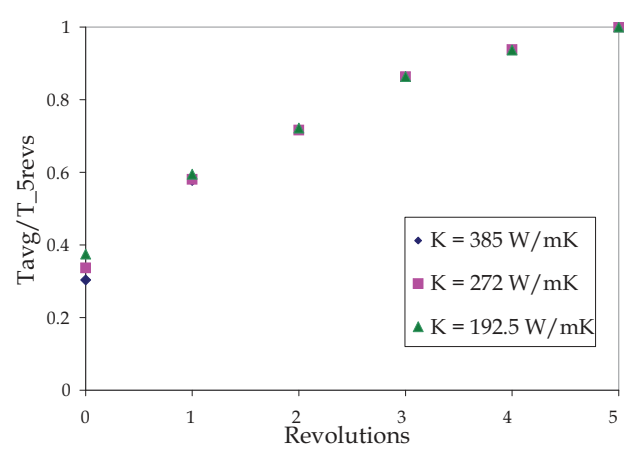

(e)

Fig. 15. (d): Comparison of the simulation data (for $\mathrm{k}_{\mathrm{s}}=385 \mathrm{~W} / \mathrm{mK}$ ) and the non-linear least square fit, (e): Average bed temperature over time for materials with different conductivities.

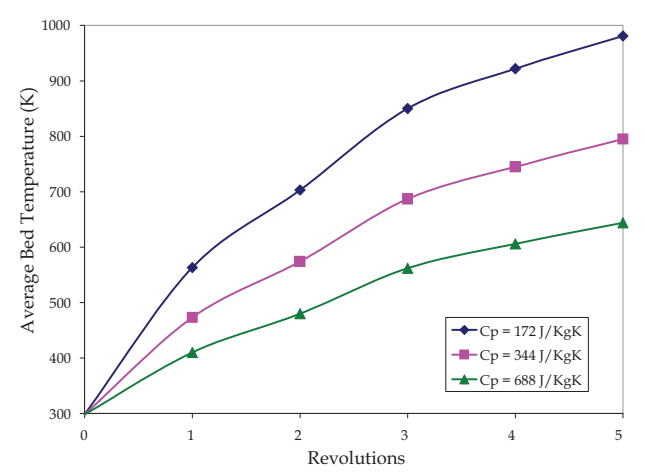

(a)

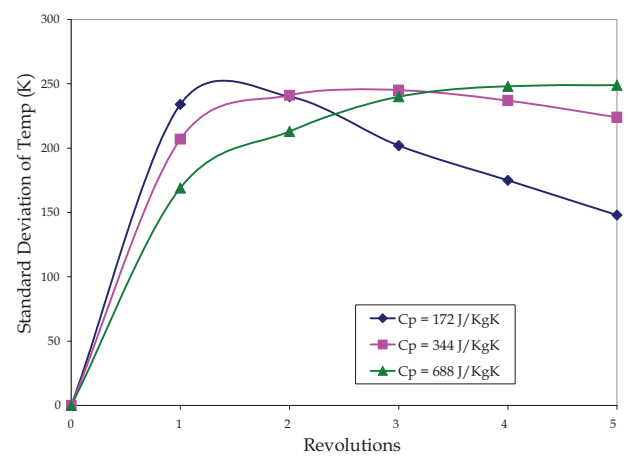

(b)

Fig. 16. (a) Evolution of average bed temperature over time in a calciner, for material with different heat capacities $(\mathrm{Cp}=172,344,688 \mathrm{~J} / \mathrm{KgK})$. Granular bed heats up faster for material with lower heat capacity (b) Variation of the standard deviation of particle temperature over time for different heat capacities. More uniformity of temperature is seen in the bed for materials of lower heat capacity. 


\subsubsection{Effect of heat capacity}

After quantifying the effect of thermal conductivity, the other main thermal property of a material, heat capacity, is checked. Three values of heat capacity of the granular material are considered: 172,344 and $688 \mathrm{~J} / \mathrm{Kg}^{\circ} \mathrm{K}$, while keeping the thermal conductivity constant at 385 $\mathrm{W} / \mathrm{m} \circ \mathrm{K}$. Once again, the calciner is rotated at the speed of $20 \mathrm{rpm}$. Average bed temperatures are estimated as a function of time (Fig. (16a)). As expected, particles with lower heat capacity exhibit faster heating. The evolution of the standard deviation of temperature of the granular bed is illustrated in Figure 16(b). The variability in the bed temperature is larger for the material with lower heat capacity until 2 revolutions, but at the end of 5 revolutions, more uniform temperature is observed for the material of lower heat capacity.

\subsubsection{Effect of granular cohesion and friction}

The effect of granular cohesion on heat transfer is examined while keeping the thermal properties constant $\left(\mathrm{k}_{\mathrm{s}}=385 \mathrm{~W} / \mathrm{m}^{\circ} \mathrm{K}\right.$ and $\left.\mathrm{Cp}=172 \mathrm{~J} / \mathrm{Kg}^{\circ} \mathrm{K}\right)$. As discussed in Section 2, to simulate different levels of cohesion and friction, the bond number $K$, the coefficients of static and dynamic friction between particles $\left(\mu_{\mathrm{SP}}\right.$ and $\left.\mu_{\mathrm{DP}}\right)$ and the coefficients of static and dynamic friction between particle and wall $\left(\mu_{\mathrm{SW}}\right.$ and $\left.\mu_{\mathrm{DW}}\right)$ are varied. Heat transfer in cohesionless particles $\left(\mathrm{K}_{\text {cohes }}=0, \mu_{\mathrm{SP}}=0.8, \mu_{\mathrm{DP}}=0.1, \mu_{\mathrm{SW}}=0.5, \mu_{\mathrm{DW}}=0.5\right)$ is compared with a slightly cohesive $\left(\mathrm{K}_{\mathrm{cohes}}=45, \mu_{\mathrm{SP}}=0.8, \mu_{\mathrm{DP}}=0.1, \mu_{\mathrm{SW}}=0.5, \mu_{\mathrm{DW}}=0.5\right)$ and a very cohesive material $\left(\mathrm{K}_{\text {cohes }}=75, \mu_{\mathrm{SP}}=0.8, \mu_{\mathrm{DP}}=0.6, \mu_{\mathrm{SW}}=0.8, \mu_{\mathrm{DW}}=0.8\right)$. The evolution of the average bed temperature over time is shown in Fig. 17a. For all cases examined here, cohesion does not cause a significant difference in the temperature profiles. The variability in bed temperature is quantified by the standard deviation of the particle temperature. In Figure $17 \mathrm{~b}$, the variation in standard deviation of temperature for the three values of cohesion is shown. Once again for the cases examined here, granular cohesion does not have a significant effect in the uniformity of the particle temperature of the bed.

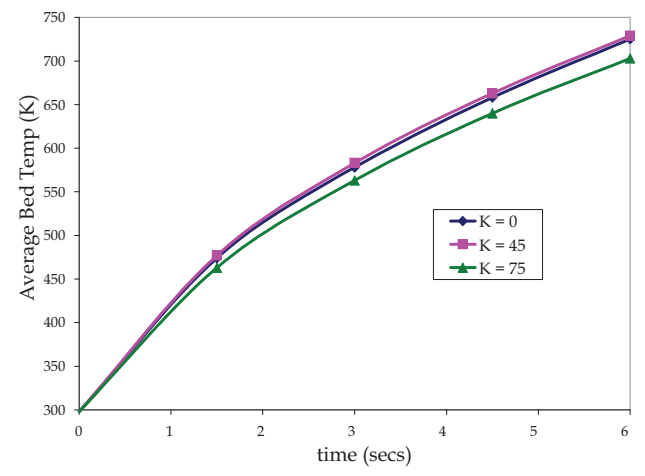

(a)

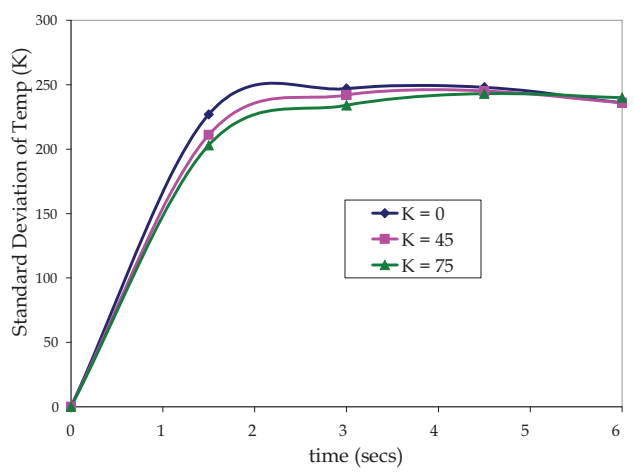

(b)

Fig. 17. (a) shows the evolution of average bed temperature over time in the calciner, for materials with different granular cohesion $\left(\mathrm{K}_{\text {cohes }}=0,45,75\right)$. (b) illustrates the variation of the standard deviation of particle temperature over time for different levels of granular cohesion. Granular cohesion has no significant effect in heat transfer. 


\subsubsection{Effect of vessel speed}

In order to examine the effect of vessel speed, the most cohesive granular system $\left(\mathrm{K}_{\text {cohes }}=\right.$ 75) is rotated at three different speeds: $12.5,20$ and $30 \mathrm{rpm}$, for thermal transport properties constant and equal to: $\mathrm{k}_{\mathrm{s}}=385 \mathrm{~W} / \mathrm{m}^{\circ} \mathrm{K}$ and $\mathrm{C}_{\mathrm{p}}=172 \mathrm{~J} / \mathrm{Kg} \mathrm{K}$. Figure 18a displays snapshots captured at $0,0.5$ and 1 revolutions for varying vessel speeds. The higher vessel speed applies a higher shear rate to the granular system, causing significant differences in flow behavior, evident in the different dynamic angle of repose of the bed at each rotational speed.

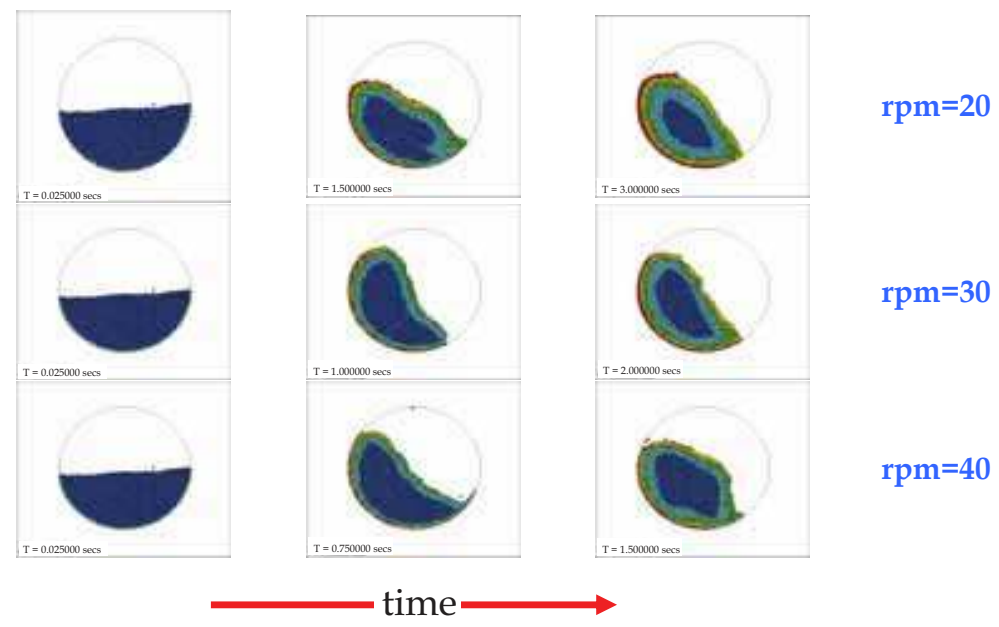

(a)

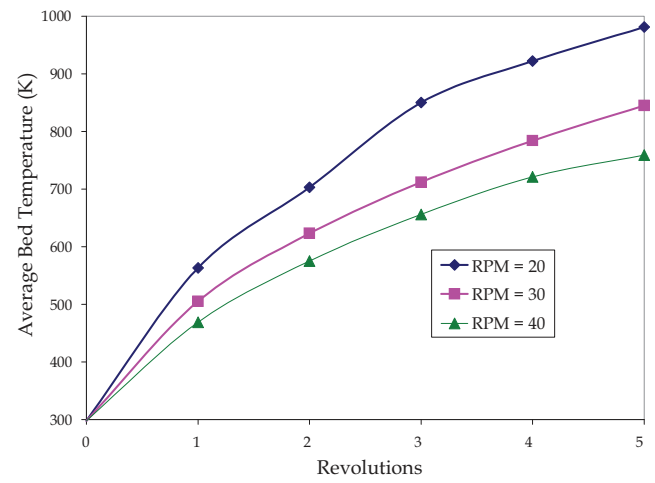

(b)

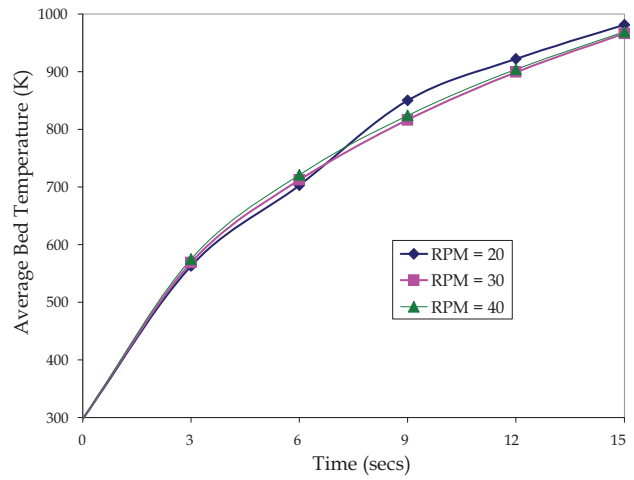

(c)

Fig. 18. (a) shows the time sequence of axial snapshots of color-coded particles in the calciner. Time increase from left to right hand side ( $T=0,0.5$ and 1 revolution), while the vessel speed increases from top to bottom (20,30 and $40 \mathrm{rpm})$. (b) shows the evolution of average bed temperature versus vessel rotations for different vessel speeds. (c) shows the average bed temperature profile over real time for different vessel speeds. Rotation speed increases heat transfer in a per-revolution basis but the effect disappears on a per-time basis. 
On a per-revolution basis, slower speed caused higher temperature rise (as shown in Fig. 18(b)). A thicker red band of particles (adjacent to the wall) and a smaller blue core are evident. At slower speeds, each particle has a more prolonged contact with the heated wall, which contributes to the rapid rise in the temperature. However, when analyzed on per absolute time basis, the effect of speed dissappers as the average bed temperatures for all the cases follows nearly identical trends (Fig 18(c)). The standard deviation of the temperature of the bed is also estimated in per-revolution and per-time basis. While the temperature of the bed is more uniform at slower speeds on a per revolution basis (Fig. 19(a)). This effect almost disappears on the real time basis (Fig 19(b)).

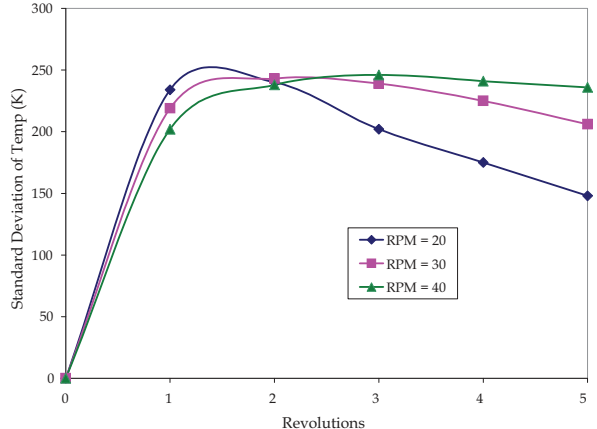

(a)

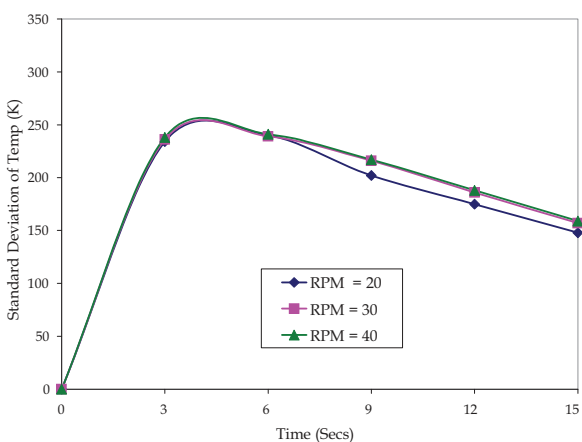

(b)

Fig. 19. (a) shows the evolution of standard deviation of bed temperature versus vessel rotations for different vessel speeds. (b) shows the standard deviation of bed temperature over real time for different vessel speeds. Rotation speed increases the uniformity of bed temperature in a per revolution basis but the effect almost disappears on a per-time basis.

\subsubsection{Effect of fill ratio}

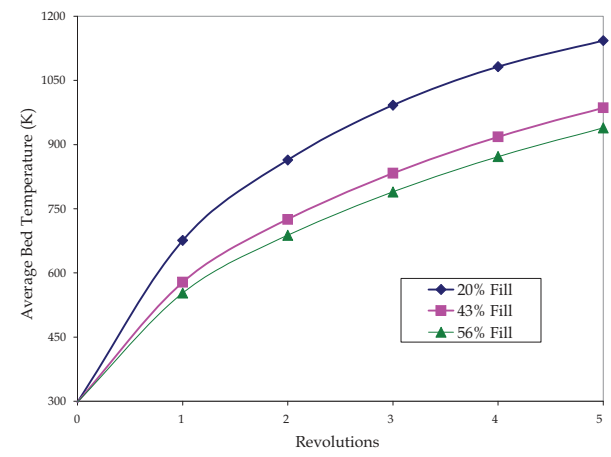

(a)

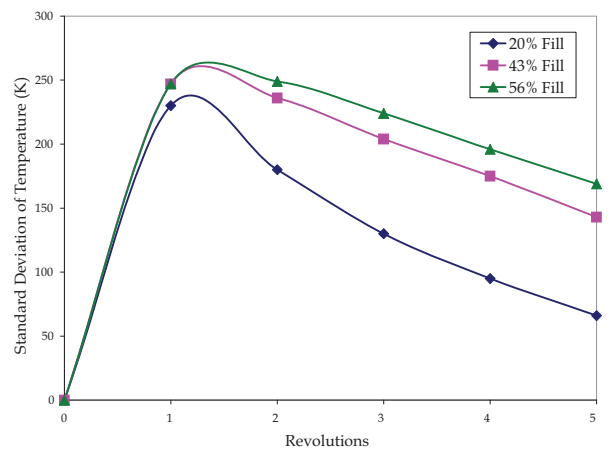

(b)

Fig. 20. (a) shows the evolution of average bed temperature over time for granular bed of different volumes (fill $\%=20,43,56$ ). The granular bed heats up faster for lower fill fraction. (b) illustrates the variation of the standard deviation of particle temperature over time for different fill fractions. More uniformity of temperature in the bed of lower fill fraction. 
Three different fill levels, 18\%, 43\% and 56\%, are simulated using 7000, 16000 and 20,000 particles. Once again, the vessel is rotated at $20 \mathrm{rpm}$. Particle's thermal transport properties remain constant at $\mathrm{k}_{\mathrm{s}}=385 \mathrm{~W} / \mathrm{m}^{\circ} \mathrm{K}$ and $\mathrm{C}_{\mathrm{p}}=172 \mathrm{~J} / \mathrm{Kg}^{\circ} \mathrm{K}$. Non-cohesive conditions are considered. In Fig. 20(a), the change in average bed temperature with time is shown as a function of the fill ratio. As expected, the granular bed with lower fill fraction heats up faster. Faster mixing is achieved for the lower fill fraction case, which causes rapid heat transfer from the vessel wall to the granular bed. The temperature is more uniform for lower fill fraction at the end of 5 revolutions (Fig 20(b)).

\subsection{Heat transfer in a double cone impregnator}

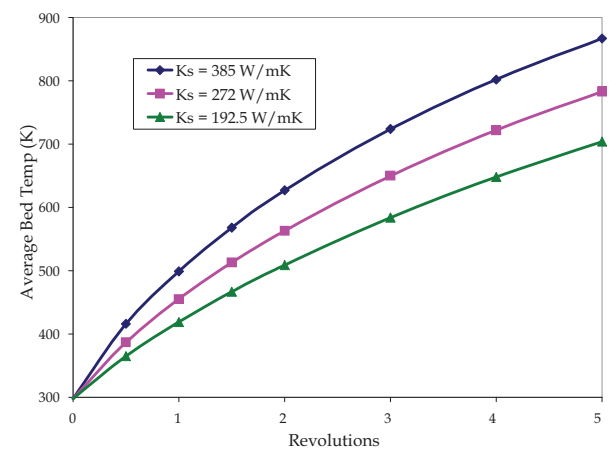

(a)

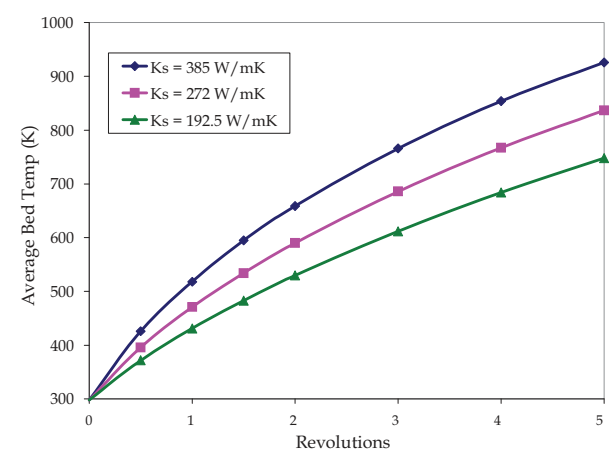

(c)

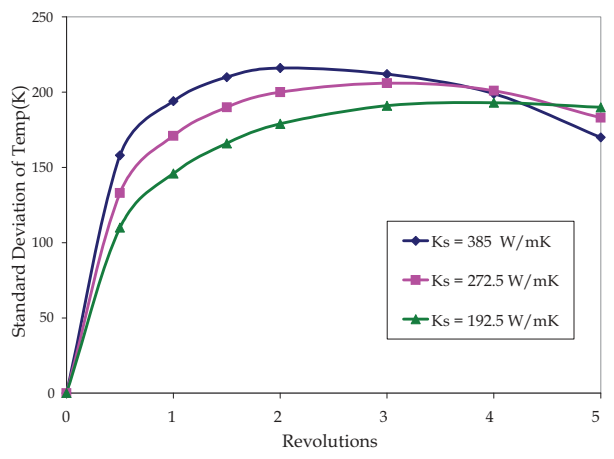

(b)

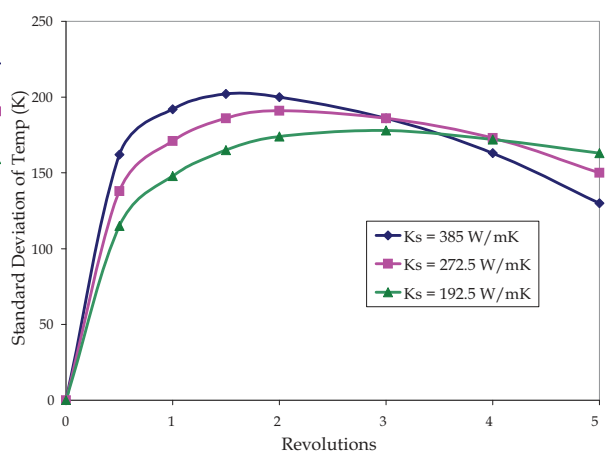

(d)

Fig. 21. (a) shows the growth of the average bed temperature over time in a non-baffled impregnator, for materials with different thermal conductivities $\left(\mathrm{k}_{\mathrm{s}}=192.5,272,385 \mathrm{~W} / \mathrm{mK}\right)$. (b) shows the growth of the average temperature of the bed over time in baffled impregnator, for materials with different thermal conductivities $\left(\mathrm{k}_{\mathrm{s}}=192.5,272,385 \mathrm{~W} / \mathrm{mK}\right)$. (c) illustrates the variation of the standard deviation of particle temperature in the nonbaffled impregnator over time for different thermal conductivities. (d) illustrates the variation of the standard deviation of particle temperature over time for different thermal conductivities for a baffled vessel. Granular bed heats up faster for material with higher thermal conductivity. 
We simulate the flow and heat transfer of 18,000 particles of $3 \mathrm{~mm}$ size rotated in a double cone impregnator equipped with a baffle of variable size. Initially, particles are loaded into the system (with and without baffles) and allowed to reach mechanical equilibrium. Subsequently, the temperature of the vessel (and the baffle) is raised to the desired value of $1298^{\circ} \mathrm{K}$, and the evolution of the temperature of each particle in the system is recorded as a function of time. All impregnator walls are considered to be frictional in the simulation. Coefficients of static friction between particles and particle-wall are considered to be 0.8 and 0.5 respectively. Coefficient of dynamic friction is considered to be the same as those of static friction for simplicity.

Firstly, the effects of thermal conductivity and heat capacity on temperature are examined. Subsequently, the impact of the vessel speed and baffle size on heat transfer rate and temperature field uniformity are examined. Three cases are considered: (a) no baffle, (b) baffle with $9 \mathrm{~cm}^{2}$ cross-section (c) baffle with $36 \mathrm{~cm}^{2}$ cross-section. Particles in all the impregnator simulations are considered non-cohesive. Once again, the initial temperature of all the particles are considered to be at $298^{\circ} \mathrm{K}$ (room temperature) whereas the temperature of the wall (and the baffle if present) is considered to be at $1298^{\circ} \mathrm{K}$ (and in isothermal condition). Particles with temperature lower than $400^{\circ} \mathrm{K}$ are colored blue, while those with temperature in between $400^{\circ} \mathrm{K}$ and $600^{\circ} \mathrm{K}$ are colored green; those with temperature in between $600^{\circ} \mathrm{K}$ and $900^{\circ} \mathrm{K}$ are colored yellow, and those with temperatures higher than $900^{\circ} \mathrm{K}$ are colored red.

\subsubsection{Effect of thermal conductivity}

Higher thermal conductivity favored the transfer of heat and enhanced temperature uniformity in calciner flows. Impregnators and calciners both tumble but have different shapes. The effect of thermal conductivity on granular bed temperature is quantified for non-baffled and baffled impregnators. Three values of thermal conductivity $\left(\mathrm{k}_{\mathrm{s}}\right)$ of the material are considered: $96.25,192.5$ and $385 \mathrm{~W} / \mathrm{m}^{\circ} \mathrm{K}$. All three simulations are performed at $20 \mathrm{rpm}$. The evolution of the average bed temperature as a function of thermal conductivity is shown in Fig. 21a (un-baffled impregnator) and 21b (baffled impregnator with baffle cross-sectional area of $\left.9 \mathrm{~cm}^{2}\right)$. More conductive particles exhibit faster heating in both cases. The standard deviation plots corresponding to particle temperature for the non-baffled and baffled impregnators are shown in Fig 21c and 21d. In the first three revolutions, we observe more uniform (lower standard deviation) temperature for the cases with lower conductivity. At later times, as most particles reach high temperatures, all the curves show low values of standard deviation (not shown). More uniform temperature is attained in the bed of highest conductivity $\left(\mathrm{k}_{\mathrm{s}}=385 \mathrm{~W} / \mathrm{mK}\right)$ after 3 revolutions (Figs. 21c and 21d).

\subsubsection{Effect of heat capacity}

Similar to the transient heat transfer analysis of the calciner, the effect of heat capacity is also quantified for non-baffled and baffled impregnators. Three values of heat capacity are considered: 172,344 and $688 \mathrm{~J} / \mathrm{Kg}^{\circ} \mathrm{K}$. The coefficient of thermal conductivity is kept constant at $385 \mathrm{~W} / \mathrm{m}^{\circ} \mathrm{K}$. These simulations are performed at a vessel speed of $20 \mathrm{rpm}$. The evolution of the average bed temperature over time is depicted in Fig. 22(a). As expected, the lower the heat capacity, the faster the rise in bed temperature. The variability of the bed temperature is higher for material with higher heat capacity (see Fig. 22(b)). 


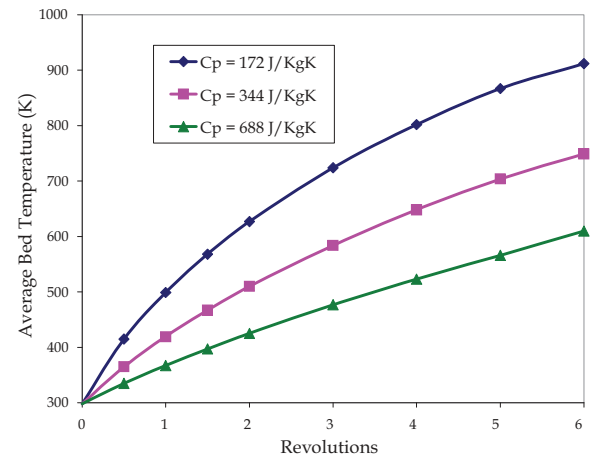

(a)

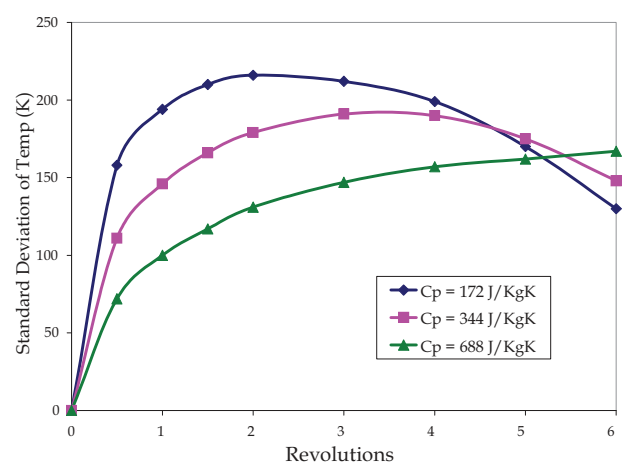

(b)

Fig. 22. (a) shows the growth of average bed temperature over time for materials with different heat capacities ( $\mathrm{Cp}=172,344,688 \mathrm{~J} / \mathrm{KgK})$. (b) illustrates the variation of the standard deviation of particle temperature over time for different baffle sizes. Granular bed heats up faster for material of lower heat capacity.

\subsubsection{Effect of baffle size}

The baffle size is a significant geometric parameter for the impregnator. The effects of baffle size on the motion and heat transfer of the granular bed are studied for three cases: (a) no baffle (b) baffle with $9 \mathrm{~cm}^{2}$ cross-section (c) baffle with $36 \mathrm{~cm}^{2}$ cross-section. Simulations are carried out for a vessel speed of $20 \mathrm{rpm}$. Thermal transport properties of the particles are $\mathrm{k}_{\mathrm{s}}$ $=385 \mathrm{~W} / \mathrm{m}^{\circ} \mathrm{K}$ and $\mathrm{C}_{\mathrm{p}}=172 \mathrm{~J} / \mathrm{Kg}{ }^{\circ} \mathrm{K}$. Figure $23(\mathrm{a})$ displays snapshots captured at $0,2.5$ and 4 seconds for varying baffle sizes. The effect of the baffle is clearly seen at the snapshot corresponding to 2.5 seconds. Red particles ( $\mathrm{T}>900^{\circ} \mathrm{K}$ ) group around the baffle boundary, whereas the un-baffled container barely contains any red particles. The average bed temperature and the standard deviation of the temperature are shown in Figs 23(b) and 23(c), respectively. The temperature increases at a faster rate (Fig. 23(b)) and more uniformly (Fig. 23(c)) for cases with baffles. The temperature rise is faster for larger baffles. Baffles enhance mixing, which increase the uniformity in the temperature field of the granular bed. This observation is line with the experimental finding by Brone, 2000 and the numerical mixing results of Muguruma, 1997, who found that an optimal baffle size and positioning enhances mixing in rotary vessels.

\subsubsection{Effect of vessel seed}

Numerical simulations of heat transfer in calciners (shown above), reveal that lower speed enhances heat transfer and temperature uniformity on a per-revolution basis. Heat transfer as a function of vessel speed is studied here for a baffled $\left(36 \mathrm{~cm}^{2}\right.$ cross sectional area) impregnator at three different rotational speeds: 12.5, 20 and $30 \mathrm{rpm}$. Transport properties are: $\mathrm{k}_{\mathrm{s}}=385 \mathrm{~W} / \mathrm{m}^{\circ} \mathrm{K}$ and $\mathrm{C}_{\mathrm{p}}=172 \mathrm{~J} / \mathrm{Kg} \mathrm{K}$, respectively. Figure $24(\mathrm{a})$ displays snapshots captured at $0,0.5$ and 1 revolutions for varying vessel speeds. At the end of 0.5 and 1 revolution, more red particles $(\mathrm{T}>900 \mathrm{~K})$ are seen for vessels rotating at lower speeds; once again, on a per-revolution basis, lower speed causes higher temperature rise (as shown in Fig. 24(b)). Again, at slower speeds, the particles have a more prolonged contact with the heated wall, which contributes to the rapid rise in the temperature. However, on a per-time basis, the effect of speed partially disappears, as the average bed temperatures rise in unison 
for first $3 \mathrm{sec}$ (Fig 24(c)) at all rotation speeds. However, after 3 seconds, temperature again rises faster for the vessel rotated at the slower speed of $12.5 \mathrm{rpm}$ giving a counter-intuitive result. The standard deviation of the temperature of the granular bed is also estimated in per-revolution and per-time basis. The uniformity of the temperature of the bed significantly increases with slower speed of the calciner on a per-revolution basis (Fig. 25(a)). This effect also remains prominent on a real-time basis (Fig 25(b)).

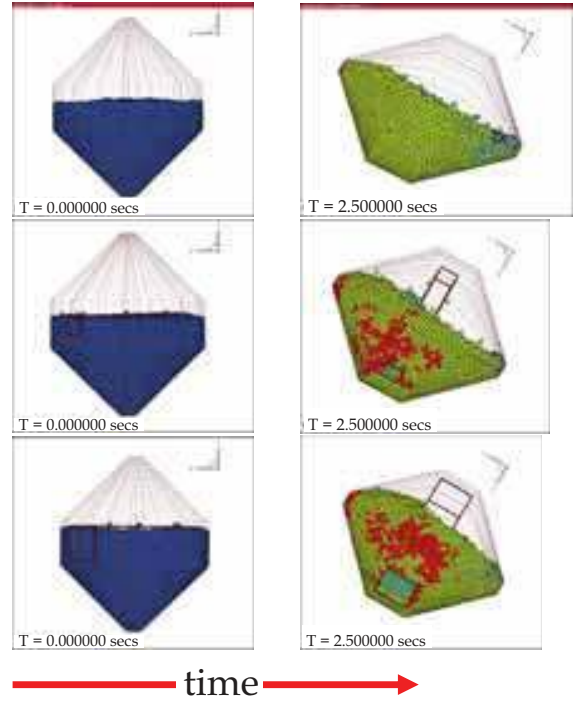

(a)

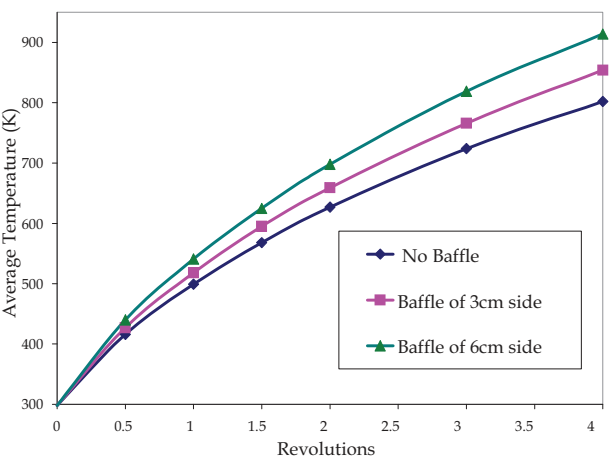

(b)

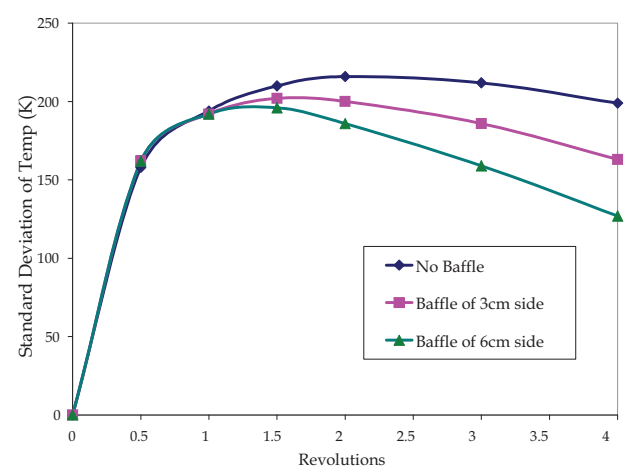

(c)

Fig. 23. (a) shows a time sequence of simulation snapshots of color-coded particles in the impregnator. Time increase from left to right hand side $(\mathrm{T}=0,2.5$ and $4.5 \mathrm{secs})$, while the baffle size increases from top to bottom (no baffle, baffle of $3 \mathrm{~cm}$, baffle of $6 \mathrm{~cm}$ ). (b) shows the growth of average bed temperature over time for different sizes of baffle. Depending on size, baffles can either increase or decrease heat transfer. (c) shows the variation of the standard deviation of particle temperature over time for different baffle sizes. Uniformity in the bed temperature is more with bigger baffle. 

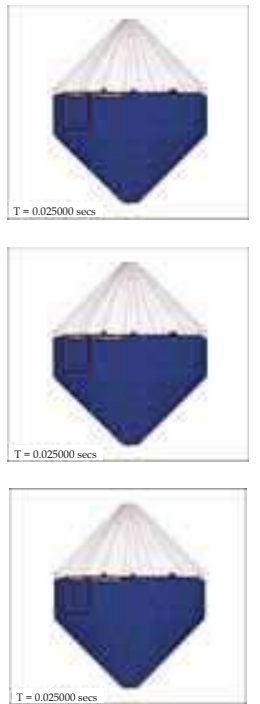
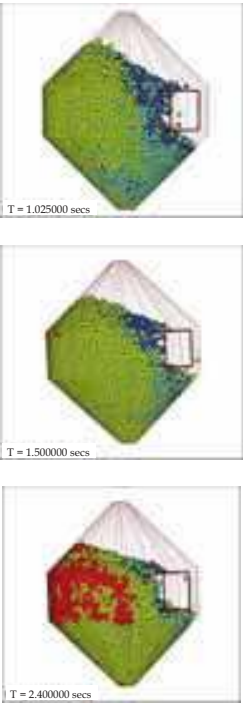

time

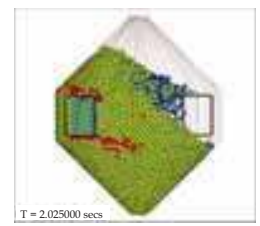

rpm $=30$

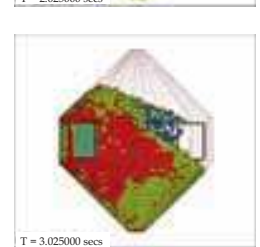

rpm $=20$

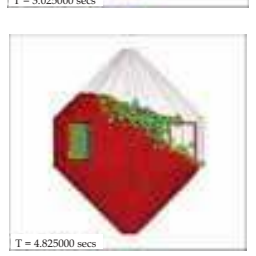

$\mathrm{rpm}=\mathbf{1 2 . 5}$

(a)

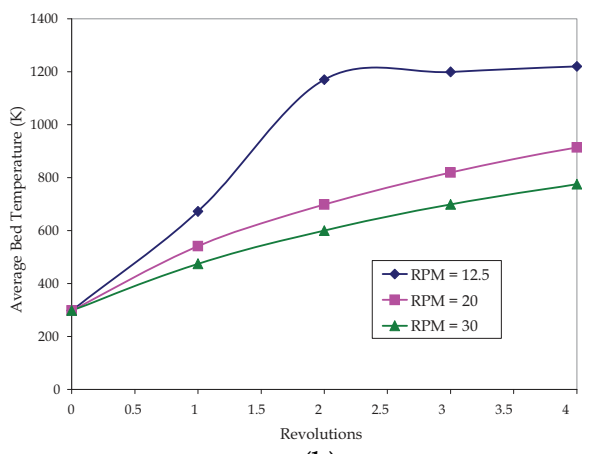

(b)

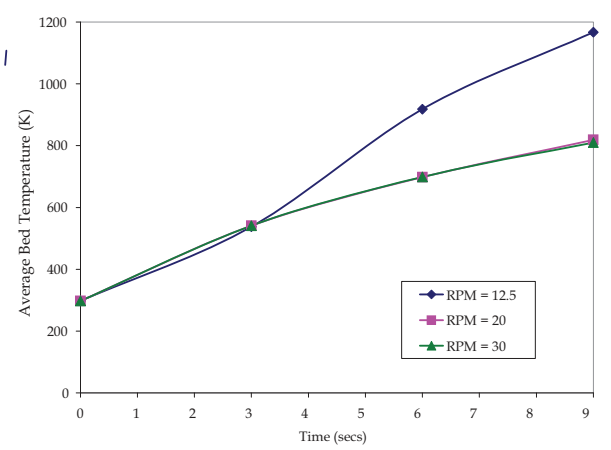

(c)

Fig. 24. (a) shows a time sequence of simulation snapshots of color coded particles in the impregnator. Time increases from left to right hand side ( $T=0,0.5$ and 1 revolution), while the vessel speed increases from bottom to top $(12.5,20,30 \mathrm{rpm})$. (b) shows the evolution of the average bed temperature versus the number of revolutions for different vessel speeds. (c) shows the growth of average bed temperature over real time for different vessel speeds. Lower rotational speed of the impregnators facilitates heat transfer if analyzed with respect to each revolution, but the effect disappears on a per-time basis.

\section{Dimensionless analysis}

Although conductivity and heat capacity of the material have similar effects in the heat transfer for both the calciner and impregnator, the vessel speed only affects the heat transfer 
in impregnators. Thus for impregnators we could define a parameter $\Pi$, which is directly proportional to the thermal conductivity $\left(k_{s}\right)$ but inversely proportional to the specific heat $\left(C_{p}\right)$ and the rotational speed $(N)$ of the vessel. The heat balance of the granular material could be expressed as:

$$
\rho C_{p}\left[\frac{\delta T}{\delta t}+v \bullet \nabla T\right]=k_{s} \nabla^{2} T
$$

or

$$
\rho C_{p} \frac{T^{0}}{\tau} \frac{\delta T^{*}}{\delta t^{*}}+\rho C_{p} \frac{U T^{0}}{L} v^{*} \bullet \nabla * T^{*}=k_{s} \frac{T^{0}}{L^{2}} \nabla^{* 2} T^{*}
$$

or

$$
\frac{\delta T^{*}}{\delta t^{*}}+\frac{U \tau}{L} v^{*} \bullet \nabla^{*} T^{*}=\frac{k_{s} \tau}{\rho C_{p} L^{2}} \nabla^{* 2} T^{*}
$$

$T^{o}, U$ and $L$ are the initial bed temperature, linear velocity and the length of the vessel respectively. If we consider $\tau=L / U$ (no independent time scale, i.e., Strouhal number $=1$ ), the equation above becomes:

$$
\frac{\delta T^{*}}{\delta t^{*}}+v^{*} \bullet \nabla^{*} T^{*}=\frac{k_{s}}{\rho C_{p} L U} \nabla^{* 2} T^{*}
$$

or

$$
\frac{D T^{*}}{D t^{*}}=\Pi \nabla^{*} T^{*}
$$

or

$$
\frac{D T^{*}}{D\left(\Pi t^{*}\right)}=\nabla^{* 2} T^{*}
$$

The dimensionless parameter $\Pi$ is expressed as follows:

$$
\Pi=\frac{k_{s}}{\rho C_{p} L U}=\frac{k_{s}}{\rho C_{p} L(2 \pi N L)}=\frac{k_{s}}{2 \pi \rho C_{p} N L^{2}}
$$

where $\mathrm{N}$ is rotational velocity in rotations per second. As per the dimensionless equation 6 , the heat transfer in the granular bed is conduction controlled. Figure 26 illustrates the variation of the dimensionless average temperatures $\left(\mathrm{T}^{*}\right)$ of the granular bed (in the impregnator with no baffle and a baffle with $36 \mathrm{~cm}^{2}$ cross-section) with dimensionless time $\left(\Pi t^{*}\right)$ as a function of either thermal conductivity or heat capacity of the material. The set of five curves ( 3 for different thermal conductivities and constant heat capacity; and 2 for different heat capacities and constant thermal conductivity) remain very close to each other 
justifying equation 6 for both the baffled and non-baffled impregnators. Thus, we observe two different groups of curves, one for baffled and one for non-baffled impregnators. The granular beds of baffled impregnator are heated faster in comparison to the non-baffled ones, which is in line to our observation in section 4.5.2. The presence of baffles, which causes a significant difference in the flow and heat transfer of granular material, brings in convective heat transport within the bed.

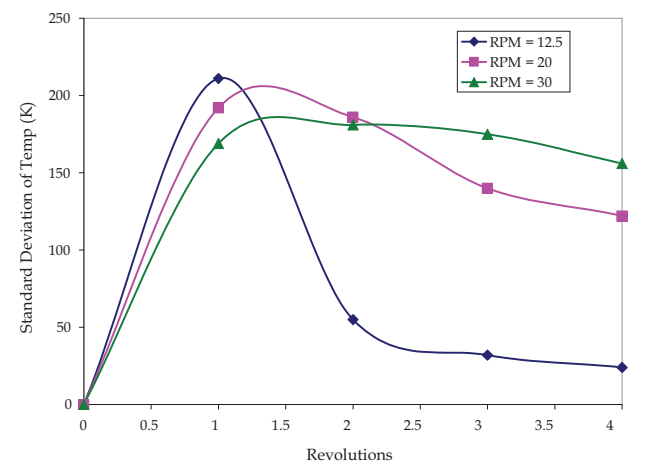

(a)

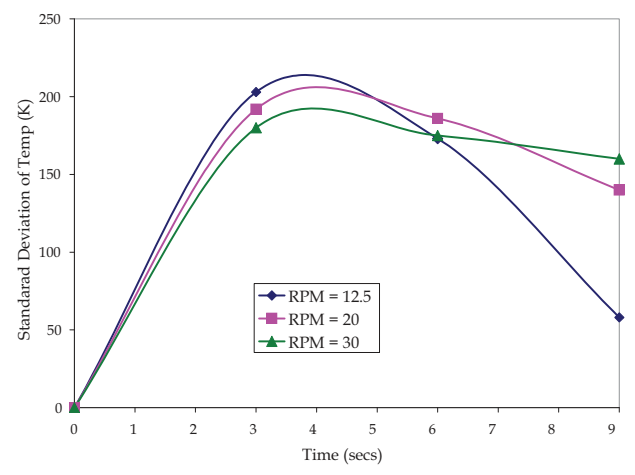

(b)

Fig. 25. (a) shows the evolution of standard deviation of the bed temperature versus vessel rotations for different vessel speeds. (b) shows the standard deviation of the bed temperature over real time for different vessel speeds. Lower rotation speed increases the uniformity of bed temperature in both per revolution and real time basis.

\section{Conclusions}

We presented experimentally validated particle dynamics simulations of heat transfer in rotary calciners. Granular flow and heat transport properties of alumina and copper are taken into account in order to develop a fundamental understanding of their effect on calcination performance. Heat transport processes are simulated accounting for initial material temperature, wall temperature, granular heat capacity, granular heat transfer coefficient, and baffle configuration. Simulations and experiments show that the rotation speed has minimal impact on heat transfer. As expected, the material with higher thermal conductivity (alumina) warms up faster in experiments and simulations. We considered various baffle configurations (rectangular and L-shaped flights) in the calciner and their effect on the flow and heat transfer of granular material. Baffles or flights enhance heat transfer and thermal uniformity. L-shaped baffles are more effective than the square shaped baffles. The average wall-particles heat transfer coefficient of the granular system is also estimated from the experimental findings. Particle dynamics simulations were also used to examine heat transfer in granular materials rotated in the impregnators. While particle movement is quite different in the impregnators and calciners, both share similar heat transfer characteristics. We observe faster heating for materials with higher conductivity and lower heat capacity. Granular cohesion does not affect heat transfer rates. Increasing rotation speed decreases heat transfer and temperature uniformity on a per-revolution basis but the effect disappears on a per-time basis. Impregnator flows also exhibit faster heating of 
the granular bed for material with higher conductivity and lower heat capacity. Baffles enhance temperature rise in the impregantors. Depending on size, baffles can either increase or decrease heat transfer in the impregnators. Lower rotational speed of the impregnators facilitates heat transfer both on a per-revolution and a per-time basis. A dimensionless parameter $\Pi$ is derived for the heat transfer in the impregnators, coupling thermal conductivity, heat capacity of the material and the rotational speed of the vessel.

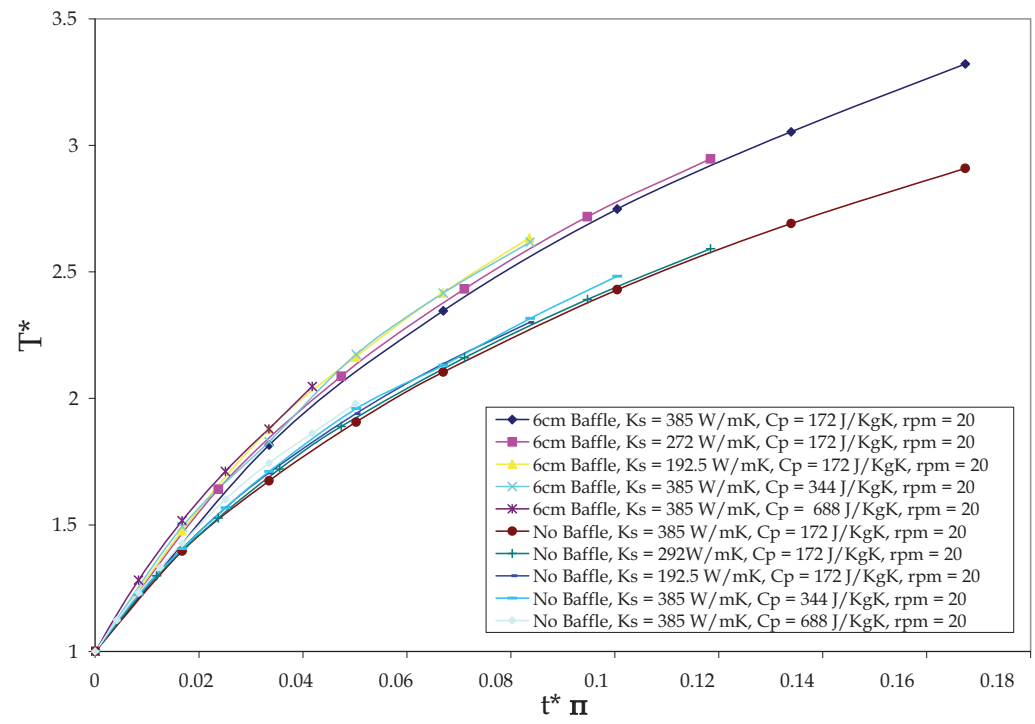

Fig. 26. The growth of dimensionless average bed temperature over dimensionless time in the baffled and non-baffled impregnators, for materials with different thermal conductivities $\left(\mathrm{k}_{\mathrm{s}}=192.5,272,385 \mathrm{~W} / \mathrm{mK}\right)$ and heat capacities $(\mathrm{Cp}=172 \mathrm{~J} / \mathrm{kgK}, 344 \mathrm{~J} / \mathrm{KgK}$ and $688 \mathrm{~J} / \mathrm{KgK})$.

Total number of particles

Radius of the particles

Density of the particles

Specific Heat

Thermal Conductivity

Thermal Diffusivity

Coefficient of restitution

Particle/particle

Particle/wall

Normal Stiffness Coefficient

Particle/particle

Particle/wall

Time step

Notations
N
$\mathbf{r}$
$\rho$
$\boldsymbol{C}_{\boldsymbol{p}}$
$\boldsymbol{k}_{\boldsymbol{s}}$
$\alpha$
$\mathrm{e}$

Table 1. Parameters employed in DEM simulations
Copper 8,000-20000

$2 \mathrm{~mm}$

$8900 \mathrm{~kg} / \mathrm{m} 3$

$172 \mathrm{~J} / \mathrm{KgK}$

$385 \mathrm{~W} / \mathrm{mK}$

$2.5 \times 10-7 \mathrm{~m} 2 / \mathrm{s}$

0.8

0.5

$\mathbf{k}$

$6000 \mathrm{~N} / \mathrm{m}$

$6000 \mathrm{~N} / \mathrm{m}$

$1-3 \times 10-6 \mathrm{sec}$
Alumina

20,000

$1.0 \mathrm{~mm}$

$3900 \mathrm{~kg} / \mathrm{m} 3$

$875 \mathrm{~J} / \mathrm{KgK}$

$36 \mathrm{~W} / \mathrm{mK}$

$1.1 \times 10-5 \mathrm{~m} 2 / \mathrm{s}$

0.8

0.5

$6000 \mathrm{~N} / \mathrm{m}$

$6000 \mathrm{~N} / \mathrm{m}$

$5 \times 10-6 \mathrm{sec}$ 


\section{Acknowledgements}

We gratefully acknowledge the support of the Rutgers Consortium on Catalyst Manufacturing Science and Engineering and Pfizer Pharmaceuticals, both grants to FJM and MST. We also acknowledge under graduate students: Myo Kyaw, Dion Zhang and Daniel Carlson for helping with the experiments.

\section{References:}

Lee, H. H. (1984). Catalyst preparation by impregnation and activity distribution. Chemical Engineering Science, 39, 859.

Lekhal, A., Glasser, B.J., Khinast, J.G. (2001). Impact of drying on the catalyst profile in supported impregnation catalysts. Chemical Engineering Science, 56, 4473.

Mickey, H.S., Fairbanks, D.F., (1955). Mechanics of heat transfer to fluidized beds. A.I.CH.E. Journal, 1,374 .

Basakov, A.P. (1964) The mechanism of heat transfer between a fluidized bed and surface. International Chemical Engineering, 4, 320.

Zeigler, E.N., Agarwal, S. (1969). On the optimum heat transfer coefficient at an exchange surface in a gas fluidized bed, Chemical Engineering Science, 24, 1235.

Leong, K.C, Lu., G.Q., Rudolph, V. (2001). Modeling of heat transfer in fluidized bed coating of cylinders. Chemical Engineering Science, 56, 5189.

Barletta, M., Simone, G. Tagliaferri, , V. (2005). A FEM model of conventional hot dipping coating process by using fluidized bed. Progress in Organic Coatings, 54, 390.

W. Schotte, Thermal conductivity of packed beds. A.I.CH.E Journal, 6, (1960) 63.

Sullivan, W.N., Sabersky, R.H. (1975). Heat transfer to flowing granular media. International Journal of Heat and Mass Transfer, 18, 97.

Broughton, J., Kubie, J, (1976) A note on heat transfer mechanism as applied to flowing granular media. International Journal of Heat and Mass Transfer, 19, 232.

Spelt, J.K, Brennen, C.E., Sabersky, R.H. (1982). Heat transfer to flowing granular material. International Journal of Heat and Mass Transfer, 25, 791.

Patton, J.S., Sabersky, R.H., Brennen, C.E. (1987). Convective heat transfer to rapidly flowing granular materials. International Journal of Heat and Mass Transfer, 30, 1663.

Buoanno, G., Carotenuto, A. (1996). The effective thermal conductivity of a porous medium with interconnected particles, International Journal of Heat and Mass Transfer, 40, 393.

Thomas, B., Mason, M.O., Sprung, R., Liu, Y.A, Squires, A.M. (1998). Heat transfer in shallow vibrated beds. Powder Technology, 99, 293.

Cheng, G.J., Yu, A.B., Zulli, Y (1999). Evaluation of effective thermal conductivity from the structure of a packed bed. Chemical Engineering Science, 54, 4199.

Wes, G.W.J, Drinkenburg, A.A.H., Stemerding, S. (1976). Heat transfer in a horizontal rotary drum reactor. Powder Technology, 13, 185.

Lehmberg, J. , Hehl, M., Schugerl, K. (1977). Transverse mixing and heat transfer in horizontal rotary drum reactors. Powder Technology, 18, 149.

Perry, H.R., Chilton, C.H. (1984). C.H. Chemical Engineers' Handbook, McGraw-Hill New York, 6, 11-46.

Lybaert, P. (1986). Wall-particle heat transfer in rotating heat exchangers, International Journal of Heat and Mass Transfer, 29, 1263. 
Boateng, A.A., Barr, P.V. (1998). A thermal model for the rotary kiln including heat transfer within the bed. International Journal of Heat and Mass Transfer, 41, 1929.

Le Page, G.P., Tade, M.O, Stone R.J. (1998). Comparitive evaluation of advanced process control techniques for alumina flash calciners. Journal of Process Control, 8, 287.

Spurling, R.J., Davidson, J.F., Scott, D.M. (2000). The no-flow problem for granular material in rotating kilns and dish granulators. Chemical Engineering Science, 55, 2303.

Sudha, O.S., Chester, A.W., Kowalski, J.A., Beekman, J.W., Muzzio, F.J. (2002). Quantitative characterization of mixing processes in rotary calciners. Powder Technology, 126, 166.

Natarajan, V.V.R., Hunt, M.L. (1996). Kinetic theory analysis of heat transfer in granular flows. International Journal of Heat and Mass Transfer, 39, 2131.

Michaelidies, E.E. (1986). Heat transfer in particulate flows. International Journal of Heat and Mass Transfer, 29, 265.

Ferron, J.R., Singh, D.K. (1991). Rotary kiln transport processes, A.I.CH.E. Journal, 37, 747.

Cook, C.A, Cundy, V.A. (1995). Heat transfer between a rotating cylinder and a moist granular bed. International Journal of Heat and Mass Transfer, 38, 419.

Cundall, P. A., (1971). A computer model for simulating progressive large-scale movements in blocky rock systems. Proceedings of Symposium International Society of Rock Mechanics, 2, 129.

Cundall, P. A., Strack, O. D. L., (1979). A discrete numerical model for granular assemblies. Geotechnique, 29, 47.

Dippel, S., Batrouni, G. G., Wolf, D. E., (1996). Collision-induced friction in the motion of a single particle on a bumpy inclined line. Physical Review E, 54, 6845.

Luding, S., (1997). Stress distribution in static two dimensional granular model media in the absence of friction. Physical Review E, 55, 4720

Thompson, P. S., Grest, G. S., (1991). Granular flow: friction and the dilatancy transition. Physical Review Letters, 67, 1751.

Ristow, G. H., Herrmann, H. J., (1994). Density patterns in two-dimensional hoppers. Physical Review E, 50, R5.

Wightman, C., Moakher, M., Muzzio, F. J., Walton, O., R., (1998). Simulation of Flow and Mixing of Particles in a Rotating and Rocking Cylinder, A.I.CH.E. Journal, 44, 1226.

Shinbrot, T., Alexander, A., Moakher, M., Muzzio, F. J. (1999). Chaotic granular mixing. Chaos, 9, 611.

Moakher, M., Shinbrot, T., Muzzio, F. J. (2000). Experimentally validated computations of flow, mixing and segregation of non-cohesive grains in 3D tumbling blenders. Powder Technology, 109, 58.

Ristow G. H (1996). Dynamics of granular material in a rotating drum. Europhysics Letters, 34, 263.

Walton, O. R., Braun, R. L., (1986). Viscosity, granular-temperature and stress calculations for shearing assemblies of inelastic, frictional disks. Journal of Rheology, 30, 949.

Walton, O. R., (1992). Particulate Two-Phase Flow, Butterworth-Heinemann, Boston.

Walton, O. R., (1993). Numerical simulation of inclined chute flows of mono disperse, inelastic, frictional spheres. Mechanics of Materials, 16, 239.

Sudah, O. S., Arratia, P. E., Alexander, A., Muzzio F. J. (2005). Simulation and experiments of mixing and segregation in a tote blender. A.I.CH.E. Journal, 51, 836.

O’Brien, R. W. O., Batchelor, G. K. (1977). Thermal or electrical conduction though granular material, Proc. R. Soc. Lond., 355, 313. 
Bird, R. B., Stewart, W. E., Lightfoot, E. N. (1960). Transport Phenomena, John Wiley and Sons, New York.

Crank, J. (1976). The mathematics of Diffusion, Oxford University Press, UK.

Brone, D., Muzzio, F. J. (2000). Enhanced mixing in double-cone blenders. Powder Technology, 110, 179.

Muguruma, Y., Tanaka, T., Kawatake, S., Tsuji, Y. (1997). Discrete particle simulation of rotary vessel mixer with baffles. Powder Technology, 93, 261. 


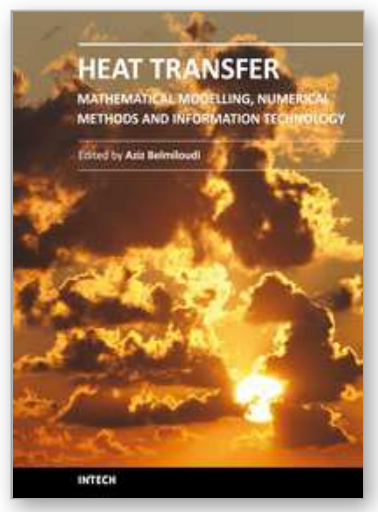

\section{Heat Transfer - Mathematical Modelling, Numerical Methods and Information Technology}

Edited by Prof. Aziz Belmiloudi

ISBN 978-953-307-550-1

Hard cover, 642 pages

Publisher InTech

Published online 14, February, 2011

Published in print edition February, 2011

Over the past few decades there has been a prolific increase in research and development in area of heat transfer, heat exchangers and their associated technologies. This book is a collection of current research in the above mentioned areas and describes modelling, numerical methods, simulation and information technology with modern ideas and methods to analyse and enhance heat transfer for single and multiphase systems. The topics considered include various basic concepts of heat transfer, the fundamental modes of heat transfer (namely conduction, convection and radiation), thermophysical properties, computational methodologies, control, stabilization and optimization problems, condensation, boiling and freezing, with many real-world problems and important modern applications. The book is divided in four sections : "Inverse, Stabilization and Optimization Problems", "Numerical Methods and Calculations", "Heat Transfer in Mini/Micro Systems", "Energy Transfer and Solid Materials", and each section discusses various issues, methods and applications in accordance with the subjects. The combination of fundamental approach with many important practical applications of current interest will make this book of interest to researchers, scientists, engineers and graduate students in many disciplines, who make use of mathematical modelling, inverse problems, implementation of recently developed numerical methods in this multidisciplinary field as well as to experimental and theoretical researchers in the field of heat and mass transfer.

\section{How to reference}

In order to correctly reference this scholarly work, feel free to copy and paste the following:

Bodhisattwa Chaudhuri, Fernando J. Muzzio and M. Silvina Tomassone (2011). Experimentally Validated Numerical Modeling of Heat Transfer in Granular Flow in Rotating Vessels, Heat Transfer - Mathematical Modelling, Numerical Methods and Information Technology, Prof. Aziz Belmiloudi (Ed.), ISBN: 978-953-307550-1, InTech, Available from: http://www.intechopen.com/books/heat-transfer-mathematical-modellingnumerical-methods-and-information-technology/experimentally-validated-numerical-modeling-of-heat-transferin-granular-flow-in-rotating-vessels

\section{INTECH}

open science | open minds

\section{InTech Europe}

University Campus STeP Ri

Slavka Krautzeka 83/A

51000 Rijeka, Croatia

\section{InTech China}

Unit 405, Office Block, Hotel Equatorial Shanghai

No.65, Yan An Road (West), Shanghai, 200040, China

中国上海市延安西路65号上海国际贵都大饭店办公楼405单元 
Phone: +385 (51) 770447

Fax: +385 (51) 686166

www.intechopen.com
Phone: +86-21-62489820

Fax: +86-21-62489821 
(C) 2011 The Author(s). Licensee IntechOpen. This chapter is distributed under the terms of the Creative Commons Attribution-NonCommercialShareAlike-3.0 License, which permits use, distribution and reproduction for non-commercial purposes, provided the original is properly cited and derivative works building on this content are distributed under the same license. 